This is a pre-copyedited, author-produced version of an article accepted for publication Socio-Economic Review following peer review. The version of record Goda, Thomas, Stewart, Chris and Torres Garcia, Alejandro (2020) Absolute income inequality and rising house prices. Socio-Economic Review, 18(4), pp. 941-976 is available online at: https://doi.org/10.1093/ser/mwz028 


\title{
Absolute Income Inequality and Rising House Prices
}

\author{
Thomas Goda ${ }^{a}$, Chris Stewart ${ }^{b}$ and Alejandro Torres García
}

\begin{abstract}
Income inequality and house prices have risen sharply in developed countries during 19752010. In line with theoretical models, we argue that this co-movement is no coincidence, but that inequality has driven up house prices on the grounds that it raises the aggregate demand for housing. Our results suggest that absolute inequality and house prices in most OECD countries were positively correlated and cointegrated, whereas relative inequality and mean income were not significant long-run determinants. This finding indicates that the surge in OECD house prices in part can be explained by a top-income-induced increase in housing demand, and that it is important to consider the interaction of rising mean income and its relative distribution when studying potential correlates of house prices. Moreover, our results confirm previous findings that the short-term real interest rate also is an important correlate of house prices.
\end{abstract}

Key Words: Personal Income Inequality, Absolute Inequality, House Prices, Asset Price Inflation, Asset Bubbles, Panel Cointegration, Bias-Corrected Fixed-Effects Dynamic Panel Estimator

JEL Classification: C23; D31; R21; R31

a Universidad EAFIT, School of Economics and Finance, Carrera 49 Número 7 Sur 50, Medellín, Colombia; email: tgoda@eafit.edu.co; phone: (57) 42619500 - 8664 (corresponding author)

b Kingston University, School of Law, Behavioural and Social Sciences, Penrhyn Road, Kingston upon Thames Surrey KT12EE, UK; e-mail: C.Stewart@kingston.ac.uk; phone: (44) 02084179000 - 62343

c Universidad EAFIT, School of Economics and Finance, Carrera 49 Número 7 Sur 50, Medellín, Colombia; email: atorres7@eafit.edu.co; phone: (57) 42619500 - 8664

We are grateful to Santiago Sanchez, Daniel Aristizabal and Germán Tabares for their excellent research assistance. We are also grateful to the participants of the International Institute of Social and Economic Sciences (IISES) 8th Economics \& Finance Conference, London, May 2017, for their helpful comments and suggestions on an earlier version of the paper. We are responsible for any remaining errors. 


\section{Introduction}

Variations in house prices can have important macroeconomic effects. Rising prices stimulate consumption expenditure and economic growth when they increase the security feeling of homeowners and ease access to credit - so called wealth and collateral effects (Case et al., 2005, 2013; Campbell, and Cocco, 2007; Hryshko et al., 2010). However, at the same time, easier access to credit can foster unsustainable debt-driven growth models and declining house prices can lead to large reductions in household consumption and prolonged recessions. Indeed, all these effects have been observed prior to, and after, the Great Recession (Hryshko et al., 2010; Mian et al., 2013; Jordá et al., 2014; Mian and Sufi, 2015; Goda et al., 2017).

Moreover, starkly rising prices can make housing unaffordable. This especially concerns the most productive urban areas and low-income households (Dewilde and Lancee, 2013; Gyourko et al., 2013) $)^{1}$. Finally, house price inflation can translate into retail price inflation (Stroebel and Vavra, 2014), which can have important implications for monetary policy and is also seen to affect mainly low-income households (see Easterly and Fischer (2001) on the latter).

Considering these potential socio-economic effects, it is not surprising that a vast literature on the dynamics of house prices exist (especially in the aftermath of the US Subprime Crisis). Typically, income is identified as an important determinant of house prices (see e.g., Case and Shiller, 2003; ECB, 2003; Sommer et al., 2013). However, in developed countries since "the final decades of the twentieth century, house price growth outpaced income growth by a substantial margin" (Knoll et al., 2017: 338).

Recent literature suggests that this phenomenon is mainly explained by low real interest rates coupled with credit expansion (Taylor, 2007; Goodhart and Hofman, 2008; Gerdesmeier et al., 2010; Agnello and Schuknecht, 2011; Bordo and London-Lane, 2013a). Other studies also

\footnotetext{
${ }^{1}$ In the UK, for example, "Homes in popular towns and London boroughs have risen to 10 and 20 times local incomes, while rents account for up to 78\% of earnings" (Collinson, 2015). However, it is important to note that "while the increase in house prices has been most pronounced in cities, it is not exclusively an urban phenomenon" (Knoll et al., 2017: 343).
} 
consider financial innovation and deregulation (Dokko et al., 2011; Bordo and London-Lane, 2013b), and global liquidity (Sá et al., 2014; Cesa-Bianchi et al., 2015) as explanatory factors.

All these determinants have in common that they are seen to increase the total demand for housing, which leads to increasing prices taking into account that land and housing supply is restricted. However, another common feature of all these determinants is that their effects mostly took place in the first decade of the twenty-first century, while house prices have increased strongly since the 1970s. The aim of the present paper is to assess rising income inequality as an additional (as yet unexamined) contributing factor for the strong increase in house prices during the period 1975-2010.

Theoretical models provide two potential mechanisms that link inequality to house prices: (i) with rising inequality the number of households that are willing to pay higher prices for their homes increases (Gyourko et al., 2013; Määttänen and Terviö, 2014); (ii) houses are an investment good for the upper part of the income distribution and in more unequal countries the investment demand is higher (Nakajima, 2005; Zhang, 2016). In both cases, the rise in demand is expected to drive up house prices when supply restrictions are considered. ${ }^{2}$

It is well established that house ownership is very unevenly distributed. In OECD countries the top $10 \%$ of the income distribution typically owns between $40 \%$ (Italy) and $60 \%$ (US) of houses, while the Gini coefficient ranges between 0.6 and 0.7 (Cowell et al., 2012), even rising to above 0.9 when only non-primary residences are considered (Bonesmo Fredriksen, 2012). It is also well established that income inequality increased starkly in most developed countries after 1980, especially due to income concentration at the top (OECD, 2015).

Considering the above, our hypothesis is that the long-run co-movement of income inequality and house prices is no coincidence, but that the increase in inequality has driven up housing demand and, in turn, their prices. To our best knowledge, no previous study has

\footnotetext{
${ }^{2}$ The view that land and house supply is restricted is backed by Knoll et al.'s (2017: 349) observation that the "surge in house prices was due to sharply rising land prices" and not due to rising construction costs.
} 
empirically tested if the stark increase in real house prices in developed countries during the last decades was partly driven by rising income inequality.

To close this gap in the literature, and test our hypothesis, the present study employs two methods. First, the bias-corrected dynamic panel fixed-effects estimator (Bruno, 2005a; 2005b) is used to quantify the impact of inequality on house prices for a panel of 15 OECD countries for the period 1975-2010. The models are estimated in autoregressive distributed lag form to recognize the evident nonstationarity of house prices, inequality and other data and thereby attempt to avoid problems of spurious regression. Second, the obtained fixed-effects results are corroborated with panel cointegration-based methods that are designed to take account for such nonstationarity of data whilst also allowing for cross-sectional dependence in the panel (Westerlund, 2007).

A further novelty of our study is that we will use both absolute and relative inequality measures to test our hypothesis. The measures for relative inequality are the Gini coefficient and the Top 5\% income share, while the variance and the market income of the Top 5\% are used as absolute inequality measures. The difference between relative and absolute inequality measures is that the former show proportional income differences, while the latter capture the interaction of relative inequality with mean income (variance) and the available income at the top (Top 5\% income).

Studies that investigate the impact of inequality on socio-economic variables like growth and crime typically only account for relative inequality measures. However, absolute and relative inequality trends tend to be quite different (see Ravallion, 2004; Atkinson and Brandolini, 2010, Goda and Torres, 2017), and we expect that absolute inequality measures are more suitable for our purpose because theoretical models argue that both the distribution and the level of income affect house prices. 
Indeed, we find that absolute income inequality and real house prices in most OECD countries are positively correlated and cointegrated in the long-run (with the notable exception of Germany, Japan, and Korea), whereas relative inequality is not. The latter is also true for real GDP per capita, although we find a significant short-run effect of mean income on house prices (as reported by Goodhart and Hofmann (2008) and Cesa-Bianchi et al. (2015)). In line with the literature discussed above, our results also suggest that low short-term real interest rates have additionally contributed to the long-run house price surge.

The layout of this paper is as follows. Section 2 details the theoretical link between inequality and house prices. Section 3 empirically tests if income inequality is a long-run correlate of house prices in OECD countries. Section 4 concludes the paper.

\section{The theoretical link between (absolute) inequality and house prices}

The theoretical models that examine whether inequality affects house prices are typically general equilibrium models that have three main conditions in common: First, the existence of heterogeneous agents, so that inequalities can be analyzed. Second, housing supply is assumed to be at least very inelastic, so that the housing market adjusts to demand shocks by price changes. Third, the presence of frictions that limit access to the housing market.

According to these models, inequality can affect house prices via two demand mechanisms. The first considers houses as consumption goods, where an increase in income inequality increases the amount of people that are willing to pay high prices for their preferred residence (Matlack and Vigdor, 2008; Gyourko et al., 2013; Määttänen and Terviö, 2014) ${ }^{3}$. The second focusses on houses as rent-generating assets, where inequality increases the absolute amount of savings, which in turn raises the demand for housing as investment assets (Nakajima, 2005;

\footnotetext{
${ }^{3}$ In general, these models assume the existence of different kinds of houses. Depending on their location or quality, some houses are preferred over others by households.
} 
Zhang, 2016). Given that the supply of housing is assumed to be limited, in both cases an inequality-induced demand increase leads to a rise in house prices.

To illustrate the theoretical mechanism, Zhang's (2016) framework is especially useful for our purpose because it considers houses as consumption goods and investment assets. The model supposes the existence of an endowment economy with two types of household: top earners with a population share of $\mu$ and an income share of $\pi$, and bottom earners with a population share of $1-\mu$ and an income share of $1-\pi$. Total income $(Y)$ and the total amount of houses $(H)$ are fixed and exogenous.

Households go through two periods, young and old. During the first period they are productive and save part of their income, while the financial return of these savings is consumed completely during the second period, when households are old and unproductive. Young households invest their savings either in bonds or houses (the amount of bonds and housing that are demanded is denoted as $b$ and $h$, respectively). Bonds are risk-free assets and pay a gross return of $1+r$, while houses as assets deliver a return of $R / P(P$ is the house price and young and old households consume housing for a rent of $R$ ). The housing market has two financial frictions: First, households have a collateral constraint, so that they cannot borrow more than a certain fraction of the value of their house $\left(\lambda_{h}\right)$. Second, the housing market has a minimum holding size requirement $(\bar{h})$. These frictions imply that not all households can participate in this market.

During each period, households derive utility from consuming output $(c)$ and housing services $(s)$. The utility function (where $\varphi$ is the weight of housing in the utility) is written as:

$$
U(c, s)=(1-\varphi) \ln (c)+\varphi \ln (s)
$$

Defining $x$ as the total expenditure during each period, and $\beta$ as the subjective discount factor, the consumption-saving problem and portfolio choice of young households can be expressed as follows: 


$$
\max \ln (x)+\beta \ln \left(x^{\prime}\right)
$$

$$
\begin{gathered}
\text { s.t. } x+b+h=y \\
x^{\prime}=(1+r) b+(P+R) h \\
b \geq-\lambda_{h} P h \\
h \in\{0,[\bar{h},+\infty]\}
\end{gathered}
$$

Guaranteeing a stationary general equilibrium, the solution of this problem allows for the determination of the prices of $R$ and $P$, the demand of $b$ and $h$, and $x$.

Accordingly, Zhang (2016) shows that within this framework the determinants of house prices are: ${ }^{4}$

$$
P=\frac{\pi}{-(1-\mu) \bar{h}+2 H}\left[\frac{\beta Y}{(1+\beta)\left(1-\lambda_{h}\right)}\right]
$$

In equilibrium, the fixed supply of housing, the high preference for housing (due to the form of the utility function) and the restrictions to participate in this market, imply that $R / P>1+$ $r$. That is, houses are always preferred as an investment asset by all households, but bottom earners have restricted access to this market and mainly save in bonds.

Equation (5) permits us to identify the main determinants of house prices, including inequality, however it is important to note that inequality can be measured in relative or in absolute terms. The former is the more widely used measure in the literature, referring to the relative income differences between the top and bottom earners in the model: $\frac{\frac{\pi Y}{\mu}}{\frac{(1-\pi) Y}{(1-\mu)}}=\frac{\pi(1-\mu)}{\mu(1-\pi)}$. Absolute inequality, on the contrary, can be understood as the absolute difference between the mean income of top and bottom earners, which can be written as $\frac{\pi Y}{\mu N}-\frac{(1-\pi) Y}{(1-\mu) N}=\frac{Y}{N}\left(\frac{\pi}{\mu}-\frac{1-\pi}{1-\mu}\right)$, where $\frac{Y}{N}$ is the mean income of the society (denoting $N$ as the total population).

\footnotetext{
${ }^{4}$ This price equilibrium is guaranteed under some specific assumptions related with the parameter values. Please see Zhang (2016) for more details.
} 
Accordingly, an important distinction between these two concepts is that relative income differences are invariant to income $(Y)$, whereas absolute ones are defined by the interaction between mean income and the relative income distribution. ${ }^{5}$ To make this point more tangible, Figure 1 shows the income distribution of three fictitious countries (A, B and C): A and B have the same relative income distribution but B has a higher mean income than A, while country $\mathrm{C}$ has the same mean income as B but its relative income distribution is more unequal. Although the relative income distribution in A and B is the same, the income distance between top and bottom earners is greater in B $(\$ 2,000)$ than in A $(\$ 1,000)$, given that B's mean income is higher. Likewise, in $\mathrm{C}$ the income distance is greater $(\$ 8,000)$ than in $\mathrm{B}$, due to $\mathrm{C}$ 's higher top income share.

\section{$<$ Figure $1>$}

With these clarifications in mind, the relationship between inequality changes and house prices becomes clear. In (5), an increase in the top earners income share $(\pi)$ is associated with an increase in house prices. The explanation for this increase is a rising housing demand by top earners, whereas the demand of bottom earners stays constant. As shown above, an increase in $\pi$ affects both relative and absolute inequality.

A similar effect on demand and prices occurs when $Y$ increases. According to the model, the resulting increase in the absolute difference between the mean income of top and bottom earners will be used by the top earners to invest in housing. As discussed above, this effect is not captured by relative inequality measures but only by absolute ones. Finally, housing demand and prices should be affected especially strongly when $\pi$ and $Y$ are changing simultaneously,

\footnotetext{
${ }^{5}$ It is important to note that the value of absolute inequality measures does not depend on the population size (see Chakravarty, 2001). Suppose, for example, the existence of two identical countries. When summing the two, mean income $\left(\frac{2 Y}{2 N}\right), \pi$ and $\mu$, will stay the same, which implies that not only absolute and relative inequality will be the same as before, but also that house prices remain constant.
} 
which typically happens. While such a simultaneous change alters both relative and absolute inequality, it affects absolute inequality more strongly.

Hence, absolute inequality measures can be expected to be more comprehensive than relative ones when trying to capture the effect of income inequality on house prices. Indeed, Figure 2 and 3 suggest that in most OECD countries real house prices are positively correlated with inequality, and that the correlation between absolute inequality and house prices is stronger than that of relative inequality.

\section{$<$ Figure $2>$ \\ $<$ Figure $3>$}

Please note that (5) also captures the price effect of a greater capacity of low-income households to participate in the housing market. That is, when the reduction of financial frictions lowers the minimum holding size requirement of low-income households $(\bar{h})$, and/or improves their access to credit $\left(\lambda_{h}\right)$. The outcome of a decrease in $\bar{h}$ and/or increase of $\lambda_{h}$ is an increase in the aggregated demand for housing and thus their prices. ${ }^{6}$

In line with this mechanism, some studies argue that the pre-crisis house price boom in the USA, Ireland and Spain was highly related with the increase of financial innovation and securitization, the strengthening and deepness of the mortgage credit market, and higher bank risk-taking (Mian and Suffi, 2009; Mian and Suffi, 2010; Addison-Smyth, 2009; Nieto, 2007; Jiménez et al., 2010). However, it is important to note that these developments mainly took place in the three above-mentioned countries, and that financial markets and developments were very heterogeneous between OECD countries (see Sá et al., 2014).

Moreover, several studies argue that income inequality and wealth concentration played an important role in explaining the credit boom and the increase of financial innovation in the

\footnotetext{
${ }^{6}$ Formally, it can be easily demonstrated in equation (5) that $\frac{\partial P}{\partial \lambda_{h}}>0$ and $\frac{\partial P}{\partial \bar{h}}<0$.
} 
USA: while income inequality contributed to the excess leverage of low- and middle-income households (Rajan 2010; van Treeck 2014; Bazillier and Hericourt 2017) ${ }^{7}$, rising wealth concentration put pressure on investors to demand collateralized debt securities (CDOs) on a mass scale (Lysandrou, 2011a; 2011b; Goda and Lysandrou, 2014). The interplay of these two developments is seen as an important driver for the financial crisis of 2007-08 and the subsequent recession (Goda et al., 2017).

To conclude, based on the theoretical model and the suggestive data that were presented in Figures 1-2, our hypothesis is that rising inequality is an important factor explaining the increase in OECD house prices during the last decades. The remainder of this paper tests whether absolute and/or relative income inequality are statistically significant drivers of house prices in OECD countries.

\section{Is (absolute) inequality a correlate of house prices?}

\subsection{The impact of inequality on house prices according to dynamic panel fixed-effects regressions}

\subsubsection{Model specification and data}

To empirically test our hypothesis, we first use a bias-corrected dynamic panel fixed-effects estimator approach that allows us to consider dynamic long-run house price effects and country specific factors. The model has the following specification:

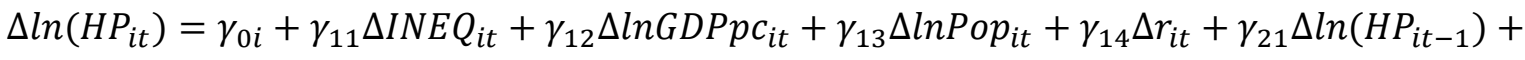

$$
\begin{aligned}
& \gamma_{22} \Delta I N E Q_{i t-1}+\gamma_{23} \Delta \operatorname{lnGDPp} c_{i t-1}+\gamma_{24} \Delta \operatorname{lnPop} p_{i t-1}+\gamma_{25} \Delta r_{i t-1}+\alpha_{1} \ln \left(H P_{i t-1}\right)+ \\
& \beta_{1} I N E Q_{i t-1}+\beta_{2} \operatorname{lnGDPpc}_{i t-1}+\beta_{3} \operatorname{lnPop}_{i t-1}+\beta_{4} r_{i t-1}+u_{t} .
\end{aligned}
$$

\footnotetext{
${ }^{7}$ Rajan (2010) and Bazillier and Hericourt (2017) also argue that the stagnant low- and middle-income households might have pushed the US government to implement aggregate demand supporting policies and encouraged the US Fed to engage in monetary expansion.
} 
where $i$ represents the country and $t$ the year, $\ln (H P)$ is the natural logarithm of the yearly averages of the OECD real house price index, INEQ denotes different income inequality measures, $\ln G D P p c$ is the natural logarithm of GDP per capita (in constant 2010 US\$), $\ln P o p$ is the natural logarithm of the population size, and $r$ is the 3-month nominal interbank interest rate (adjusted with consumer price inflation). We estimate models involving various combinations of the variables specified in (6); however, we always include $\gamma_{0 i}$, being the crosssectional fixed-effects.

We use the bias-corrected dynamic panel fixed-effects estimator discussed by Bruno (2005a; 2005b) because the conventional fixed-effects estimator is known to be biased (see Nickell, 1981). It is also more appropriate for panels with the small number of cross-sectional units $(N)$ that we have than the typically employed alternative estimators of, for example, Arellano and Bond (1991), Arellano and Bover (1995) and Blundell and Bond (1998) that are only consistent as $N$ tends to infinity. ${ }^{8}$ For all estimated fixed-effects models we use the Anderson and Hsiao (1982) estimator to obtain initial parameter estimates, the highest degree of accuracy in the bias correction (being an approximation up to $O\left(N^{-1} T^{-2}\right)$ ) and 800 replications in the bootstrapping of coefficient standard errors.

These models are estimated in autoregressive distributed lag (ADL) form (involving differenced and levels variables) given our nonstationary data (see Appendix for unit root tests). The first differencing of I(1) variables ensure these differenced terms are stationary while the levels terms form a stationary linear combination if there is cointegration. Provided there is cointegration the estimates and test statistics will not be subject to spurious regression; however,

\footnotetext{
${ }^{8}$ The fixed-effects estimator (least-squares dummy variable, LSDV, or using time demeaned data) will suffer from dynamic panel bias and inconsistency (as $\mathrm{N}$ tends to infinity) when $T$ is small. Nevertheless, when $T$ increases the bias and inconsistency of the fixed-effects estimator eventually disappears. However, Roodman (2006, pp. 17-18) notes that even when $T=30$ substantial bias $(20 \%)$ can still remain in the estimator. We do not use dynamic panel generalised methods of moments (GMM) estimators (see, Arellano and Bond, 1991; Arellano and Bover, 1995; Blundell and Bond, 1998) because they are only consistent as $N$ tends to infinity. Our panels have $N=18$ and $N=15$ which would not be regarded as large enough to obtain consistent estimates using these methods (see, Roodman, 2009).
} 
in the absence of cointegration the inferences from the model will not be valid. We can therefore only draw valid inference for sets of variables where there is cointegration (see our Westerlund tests below). The ADL form also allows us to identify whether covariates have a significant impact on house prices in the long-run and/or short-run.

In accordance with the above discussed theoretical model and distinction between absolute and relative inequality measures, we account for the Top $5 \%$ income share $\left(T o p 5 \%{ }_{i t}\right)$ and the market income of the Top $5 \%$ earners in constant US\$ $(\ln (T o p 5 \$ i t))$. Given that it is likely that the demand for housing is not solely influenced by top earners, the widely used Gini coefficient $\left(\operatorname{Gini}_{i t}\right)$ and income variance $\left(\ln \left(\operatorname{Var}_{i t}\right)\right)$ are additionally considered to measure relative and absolute changes in the overall distribution. The main difference between the Gini coefficient and the variance is that the former normalizes the sum of income differences with the mean income, whereas the variance subtracts the mean income from individual incomes. ${ }^{9}$

The market Gini coefficient is retrieved from Solt's Standardized World Income Inequality Database. The SWIID combines and adjusts Gini coefficients from different sources and currently is the most extensive publicly available database of income Gini coefficients that are comparable across countries and time. ${ }^{10}$ SWIID data have been widely used in previous studies concerned with income inequality. ${ }^{11}$

The three other inequality variables are all estimated, given that they are not readily available for the sample. Following Goda and Torres García (2017), we first estimate ventile income shares $\left(x_{p i t}\right)$ for each country and year under study (among them Top $5 \%_{i t}$ ). The ventile income

\footnotetext{
${ }^{9}$ See Chakravarty (2001) for an in depth-discussion about the similarities and differences between these two inequality measures.

${ }^{10}$ Please note that the procedure and the quality of the imputations of SWIID's Version 4.0 has been heavily criticized by Jenkins (2015). However, we are using Version 5.0 of the SWIID and, according to Solt (2015), most of these shortcomings have been superseded in this version.

${ }^{11}$ See, for example, Bergh and Nilsson (2010), Fox and Hoelscher (2012), Agnello and Soussa (2014), Herzer et al. (2014), Chon (2015) and Goda and Torres García (2017).
} 
shares enable us to derive the per capita income of each ventile ${ }^{12}$ (including $\ln \left(\operatorname{Top} 5 \$_{i t}\right)$ ), which is used to calculate the variance:

$$
\operatorname{Var}_{i t}=\frac{1}{20} \sum_{p=1}^{20}\left(\operatorname{VENTILEPc}_{p i t}-G D P p c_{i t}\right)^{2}
$$

Mean income, population size and interest rates have been chosen as control variables because these are the most widely mentioned determinants of house prices. Higher mean income and a rise in population are expected to foster the demand for housing (see e.g., Case and Shiller, 2003). The same applies to low real interest rates, which increase the access to, and lower the financing costs of, mortgages. Hence expansionary monetary policy is the most studied potential driver behind the upsurge in OECD house prices (see e.g., Taylor, 2007; Goodhart and Hofman, 2008; Gerdesmeier et al., 2010; Agnello and Schuknecht, 2011; Dokko et al., 2011, Bordo and Landon-Lane, 2013a).

For the period 1975-2010 annual data for all of these variables is available for 18 OECD countries: Australia (AUS), Belgium (BEL), Canada (CAN), Denmark (DEN), Finland (FIN), France (FRA), Germany (GER), Ireland (IRE), Italy (ITA), Japan (JAP), the Netherlands (NET), New Zealand (NEW), Norway (NOR), South Korea (KOR), Spain (SPA), Sweden (SWE), the UK (UKD) and the USA (USA).

However, we excluded Germany, Japan and Korea from the regressions because real house prices in these countries experienced a decline in the post-1990 period (see Figure 1 in Section 2), which stands in stark contrast to the price rise in the other 15 countries; hence, questioning the homogeneity of coefficients across all 18 sample countries. ${ }^{13}$ In the case of Germany, this dissimilar pattern is partly explained by the relatively low share of home ownership,

\footnotetext{
${ }^{12}$ VENTILEPc $c_{\text {pit }}=x_{\text {pit }} * G D P p c_{i t} / 0.05$.

${ }^{13}$ The exclusion of these countries is also backed by unreported results from cointegrating equations of house prices on inequality measures (where cointegration was evident) by dynamic ordinary least squares (DOLS) for each of the 18 countries. These results suggest homogeneity of coefficients for only 15 of the countries and raise serious doubts that this homogeneity extends to Germany, Japan and Korea. These unreported results are available upon request from the authors.
} 
governmental regulation and the reunification of East- and West-Germany (Hilbers et al., 2008); in the case of Japan, by the bust of the house price boom in 1990, and the subsequent crisis and debt overhang (Krainer et al., 2010); and in the case of Korea, by governmental price controls and a massive increase in governmental housing supply (Kim and Cho, 2010).

\subsubsection{Results}

Table 1 reports the results for the panel of 15 OECD countries. The results do not reveal any clear long-run determinants of house prices for the period 1975-2010, given that none of the lagged levels of the explanatory variables are statistically significant. The results do indicate, however, significant short-run effects of current GDP per capita growth on house prices growth. The finding that GDP growth affects house price growth positively is in line with the findings of previous studies (see e.g., Goodhart and Hofmann, 2008; Cesa-Bianchi et al., 2015).

\section{$<$ Table $1>$}

Moreover, the lagged level of house prices seems important to explain house price changes and house price error-correction behavior is evident (that is, $\ln (H P)_{t-1}$ is statistically significant). While this finding suggests the need to use a dynamic panel estimator (such as the one we adopt), that there may be long-run effects and that the coefficient on $\ln (H P)_{t-1}$ is broadly homogeneous for the sample countries, it remains unclear what the long-run determinants of house prices are.

One likely reason explaining why all non-house price level variables are insignificant could be multicollinearity. GDP per capita is used to calculate absolute inequality (see (7) and Footnote 12), so that $\ln (\operatorname{Var})$ and $\ln (\operatorname{Top} 5 \$)$ are strongly correlated with $\ln (G D P p c)$. The simple correlation coefficient for $\ln (G D P p c)$ with $\ln ($ Var $)$ is 0.74 and with $\ln (T o p 5 \$) 0.87$ 
(see Table 1A in the Appendix), suggesting a high degree of imperfect collinearity between these pairs of variables. ${ }^{14}$

Multicollinearity effects are known to reduce the precision of the estimation of parameters and can make coefficients appear insignificant when they would be significant in a more parsimonious specification. Moreover, they can make coefficient estimates very sensitive to small changes in data and potentially cause a change in the signs of coefficients - Asteriou and Hall (2016, p. 109) point out that in the presence of imperfect multicollinearity the “... signs of the estimated coefficients can be the opposite of those expected."

To consider whether the results are influenced by potential multicollinearity (and lack of precision in estimation ${ }^{15}$ ), and to disentangle the effects of the two variables, we therefore consider what happens if we omit either $\ln (G D P p c)$ or the $I N E Q$ variables from the panel regressions. ${ }^{16}$ According to Table 2, the lagged level of mean income remains insignificant when the inequality variables are omitted from the regression. This consistent lack of an evident long-run effect of $\ln \left(G D P p c_{t}\right)$ is surprising; however, it is in line with some previous empirical findings (see e.g., Gallin, 2006; Mikhed and Zemcik, 2009; Knoll et al., 2017).

\section{$<$ Table $2>$}

In line with mean income, the relative inequality measures are also not significant in any of the regressions when income is excluded from the model. However, the lagged level of the two absolute inequality measures (as well as their short-run differenced contemporaneous coefficients) become significant when mean income is omitted from the regression, which

\footnotetext{
14 The simple correlation coefficients between $\ln (G D P p c)$ and the other levels covariates included in the regressions in Table 1 and Table 2 are much lower, suggesting little problem of collinearity for these variables. That is, its correlation coefficient with Gini is 0.14 , with $T o p 5 \%$ is 0.13 , with $r_{t}$ is 0.11 and with $\ln (P o p)$ is -0.13 .

15 There may also be some lack of precision in estimation when including the current and first differences as well as the lagged levels of all variables in the model. This issue can be addressed by considering the exclusion of some variables from the model.

${ }^{16}$ Please note that the main results of Sections 3.1.2 and 3.2.2 do not change when overall income (real GDP) is considered as an explanatory variable (instead of real GDP per capita).
} 
indicates that the surge in OECD house prices is partly explained by the rise in absolute income inequality. This finding is in line with the theoretical model discussed in Section 2 and the stylized fact that house ownership is very unevenly distributed in the OECD (see Cowell et al., 2012), and suggests that housing demand partly depends on the absolute amount of income at the top.

Given the double log specification, the coefficients can be interpreted as follows: according to the overall absolute inequality measure $\left(\operatorname{Var}_{t}\right)$ a $1 \%$ rise in absolute inequality leads to an approximate $0.36 \%$ long-run increase in real house prices, while a $1 \%$ rise in the Top $5 \%$ market income $(T o p 5 \$ t)$ leads to an approximate $0.69 \%$ long-run increase in real house prices. ${ }^{17}$

In addition to absolute inequality, the lagged level of the real interest rates shows a significant negative effect in the two regressions where absolute inequality is considered (and mean income is omitted). This effect is expected theoretically and in line with previous findings (as discussed in Section 3.1.1). Population size, on the other hand, is not significant in any of the regressions.

Given that the absolute inequality measures (and the short-term real interest rate) are only significant at the $10 \%$-level, we proceed with Westerlund cointegration tests to further investigate our findings. The significance of the lagged level of house prices at the $1 \%$-level in all regressions with 15 countries in the panel, as well as the data from Figure 1, suggests that house prices are not stationary and can be interpreted as a sign of cointegration. ${ }^{18}$ Hence, it may be a lack of precision in estimation using the fixed-effects models that is making it difficult to uncover the significant long-run explanatory factors of house prices.

\footnotetext{
17 The approximate long-run effect is calculated as follows (where the coefficients refer to equation (6) above): $-\frac{\beta_{1}}{\alpha_{1}}$

${ }^{18}$ House prices could be deemed stationary if the coefficient on $\ln (H P)_{t-1}$ is negative and significant and all other lagged level terms' coefficients are insignificant (the so called lagged degenerate independent variables case) - see McNown et al. (2018).
} 


\subsection{Are Real House Prices and Income Inequality Cointegrated?}

\subsubsection{Determining stationary, cointegration and causality}

To establish if the necessary condition for cointegration between real house prices $\left(\ln \left(H P_{t}\right)\right)$ and the explanatory variables is satisfied, first Pesaran's (2007) panel unit root test (based upon truncated CADF statistics) is applied. In a second step Cerrato et al.'s $(2009,2011)$ heterogeneous nonlinear panel unit root test is used. Both tests account for cross-sectional dependence and we apply the sequential panel selection method (SPSM), proposed by Chortareas and Kapetanios (2009), to identify which cross-sections (countries) are stationary and which are nonstationary.

The Cerrato et al. $(2009,2011)$ test assumes nonlinear adjustment (possibly approximating structural breaks) whereas the Pesaran (2007) test assumes linear adjustment. Since each test is most powerful for the adjustment it is designed for we infer stationarity if either test indicates stationary. Further, if either test suggests trend stationarity and neither indicates stationarity we will infer trend stationarity. Otherwise, we infer a unit root (please see the Appendix for a more detailed discussion of the procedure).

We proceed to test for cointegration between $\ln \left(H P_{t}\right)$ and $I N E Q_{t}, \ln \left(G D P p c_{t}\right), \ln \left(P_{0} p_{t}\right)$, and $r_{t}$ by applying Westerlund's (2007) panel cointegration test, which is based on the following model assuming a single cointegrating vector:

$$
\Delta y_{i, t}=\delta_{1, i}+\delta_{2, i} t+\alpha_{i} y_{i, t-1}+\lambda_{i}^{\prime} \boldsymbol{x}_{i, t-1}+\sum_{j=1}^{p_{i}} \alpha_{i j} \Delta y_{i, t-j}+\sum_{j=-q_{i}}^{p_{i}} \boldsymbol{\gamma}_{i j}^{\prime} \Delta \boldsymbol{x}_{i, t-j}+e_{i, t}
$$

where, $x_{i, t}^{\prime}=\left(\begin{array}{llll}x_{1, i, t} & x_{2, i, t} & \cdots & x_{K, i, t}\end{array}\right)$ is a vector containing $K$ explanatory variables that are assumed to be weakly exogenous while the inclusion of $q_{i}$ lead values prevents the violation of strict exogeneity. The number of leads and lags is chosen to minimise Akaike's information criterion (AIC) as implemented with Persyn and Westerlund's (2008) Stata program.

The null of no cointegration for any cross-sectional unit, $H_{0}: \alpha_{i}=0 \forall i$, is tested against two different alternative hypotheses. The two group mean statistics, denoted $G_{\tau}$ and $G_{\alpha}$, specify 
the alternative as cointegration for at least one cross-sectional unit: $H_{1}^{G}: \alpha_{i}<0$, that is, for at least one i. $G_{\alpha}$ utilises a heteroscedasticity and autocorrelation consistent (HAC) adjustment where we set the bandwidth parameter using: $M_{i}=4\left(\frac{T}{100}\right)^{2 / 9}$, giving $M_{i}=3 .{ }^{19}$ The two panel statistics, denoted $P_{\tau}$ and $P_{\alpha}$, specify the alternative hypothesis that there is cointegration for all cross-sectional units, that is, $H_{1}^{P}: \alpha_{i}<0 \forall i .^{20}$

The Westerlund (2007) test assumes weak exogeneity and we asses this assumption by, firstly, applying the Westerlund (2007) test to the reverse regression of inequality on house prices. ${ }^{21}$ Furthermore, we use a more typical test for weak exogeneity that is based on the errorcorrection form of a vector autoregression (VAR), typically referred to as the restricted vector error correction model (VECM) or VEC. The VEC, assuming one cointegrating equation with (unrestricted) intercept and no trend, in this two-variable system would be specified as follows for country $i$ :

$$
\begin{aligned}
& \Delta \ln \left(H P_{t}\right)=\gamma_{11}+\sum_{j=1}^{p} \gamma_{12 j} \Delta I N E Q_{t-j}+\sum_{j=1}^{p} \gamma_{13 j} \Delta \ln \left(H P_{t-j}\right)+\alpha_{1}\left[\ln \left(H P_{t-1}\right)-\beta_{2} I N E Q_{t-1}\right] \\
& \Delta I N E Q_{t}=\gamma_{21}+\sum_{j=1}^{p} \gamma_{22 j} \Delta I N E Q_{t-j}+\sum_{j=1}^{p} \gamma_{23 j} \Delta \ln \left(H P_{t-j}\right)+\alpha_{2}\left[\ln \left(H P_{t-1}\right)-\beta_{2} I N E Q_{t-1}\right]
\end{aligned}
$$

When applying long-run Granger non-causality (LRGNC) tests we estimate system (9) for each country with time-series regressions, using previously specified cointegrating equations to define the error-correction terms. ${ }^{22} \mathrm{We}$ subtract the mean of these error-correction terms to

\footnotetext{
${ }^{19}$ We set the maximum number of lead and lags in (8) to 3.

${ }^{20}$ The four panel cointegration statistics are normalised using the asymptotic moments reported in Westerlund (2007, Table 1) and have an asymptotic standard normal distribution. Any normalised statistic that is less negative (greater) than the left-tail critical value implies that the no cointegration null should not be rejected. We report bootstrapped probability values (using 800 replications), that are robust to very general forms of cross-sectional dependence, as produced by Persyn and Westerlund's (2008) program. We find that when cointegration is supported it is based on at least one of the panel statistics suggesting cointegration for the whole panel of countries. ${ }^{21}$ Please note that this method of assessing weak exogeneity is only suggestive because the cointegrating equations in the autoregressive distributed lag (ADL) models are different when the difference of $\ln \left(H P_{t}\right)$ is the dependent variable and when the difference of inequality is the dependent variable; and because only leads and lags of the differenced regressors are included in the ADL model.

${ }^{22}$ The null of weak exogeneity uses t-tests on $\alpha_{1}$ and $\alpha_{2}$ with the following alternative hypotheses: $H_{A}^{1}: \alpha_{1} \neq 0$ implies that $I N E Q_{t}$ Granger-causes $\ln \left(H P_{t}\right)$ in the long-run. $H_{A}^{2}: \alpha_{2} \neq 0$ implies that $\ln \left(H P_{t}\right)$ Granger-causes $I N E Q_{t}$ in the long-run. LRGNC tests are only applied to models with evident cointegration because the errorcorrection term will only be stationary if there is cointegration. Without cointegration, standard critical values used in the LRGNC tests are inappropriate due to a spurious significance problem (see Stewart, 2011).
} 
produce new zero mean error-correction terms to be used in a slightly modified version of (9). The lag lengths for each country are determined using the AIC with a maximum lag of $p=3$.

\subsubsection{Results}

The panel unit root tests suggest that $\ln \left(H P_{t}\right), \ln \left(G D P p c_{t}\right)$ and our four inequality measures are at least I(1) for the vast majority of the 15 countries that are regarded as broadly homogeneous in terms of our analysis (see Appendix). To be more precise, according to at least one of the two test, the number of countries where the series are found to be I(1) are: 10 for $\ln \left(H P_{t}\right), 13$ for $\ln \left(G D P p c_{t}\right), 12$ for $\operatorname{Gini}_{t}, 11$ for $T o p 5 \% t, 14$ for $\ln \left(\operatorname{Var}_{t}\right)$, and 13 for $\ln \left(\operatorname{Top} 5 \$_{t}\right){ }^{23}$

That not all countries' variables are I(1) may be due to factors such as Type I errors. Hence, we treat all series as if they are I(1), satisfying the necessary condition for cointegration, and proceed to conduct tests of cointegration. ${ }^{24}$ If the assumption that the necessary condition for cointegration being satisfied is incorrect this will likely manifest itself in the rejection of cointegration and/or the theoretical implausibility of the estimated cointegrating equation.

We therefore proceed to test for bivariate cointegration between $\ln \left(H P_{t}\right)$ and $I N E Q_{t}$ or $\ln \left(G D P p c_{t}\right)$ by applying Westerlund's (2007) panel cointegration test (Table 3). For the two relative inequality measures, Gini $_{t}$ and $\mathrm{Top} \%_{t}$ (columns 4-5), all four tests for both sets of deterministic terms cannot reject the null hypothesis. Hence, it is unambiguous that there is no evidence of cointegration between $\ln \left(H P_{t}\right)$ and Gini $_{t}$ or $T o p 5 \%$. The same is broadly true for $\ln \left(G D P p c_{t}\right)$, where only one of the eight test suggests cointegration (column 6).

$\operatorname{Ln}\left(\operatorname{Var}_{t}\right)$ and $\ln \left(\operatorname{Top} \$_{t}\right)$, on the other hand, pass all tests of cointegration but one (columns 2-3). The evidence in favor of cointegration between these two variables and $\ln \left(H P_{t}\right)$ is

\footnotetext{
${ }^{23}$ When considering the whole sample of 18 countries, the number that are found to be $\mathrm{I}(1)$ are: 13 for $\ln \left(H P_{t}\right)$, 16 for $\ln \left(G D P p c_{t}\right), 15$ for Gini $_{t}, 14$ for $T o p 5 \% t, 17$ for $\ln \left(\operatorname{Var}_{t}\right)$, and 16 for $\ln \left(\operatorname{Top}_{5} \$_{t}\right)$.

${ }^{24}$ If some of the series are $\mathrm{I}(0)$ this should not be an issue because the ADL method can identify error-correction relationships when some series are I(1) and others are I(0), see Pesaran et al. (2001).
} 
especially strong when the intercept is the only deterministic term included in the model, where all tests indicate cointegration at least at the 5\%-level of significance.

\section{$<$ Table $3>$}

Given the evidence in favor of cointegration with homogeneous long-run coefficients across all 15 countries for both absolute measures of inequality we report their implied estimated homogeneous long-run relationships in Table 4. We favor inference from the models where the intercept is the only deterministic term. ${ }^{25}$ In line with the results presented in Table 2 (Section 3.1.2), in these long-run models the inequality measures are both significant (at the 1\%-level) and exhibit the expected positive coefficient sign. Hence, it can be concluded that the two absolute inequality measures are an important correlate of house prices in this sample of countries. This finding is theoretically expected (as discussed in Section 2), and in line with the dynamic panel fixed-effects results.

\section{$<$ Table $4>$}

The Westerlund (2007) panel cointegration tests on the reverse regression with inequality as the dependent variable regressed on $\ln \left(H P_{t}\right)$ reject cointegration for all four inequality measures and $\ln \left(G D P p c_{t}\right)$ regardless of the deterministic specification (Table 5). This suggests that inequality and real per capita income is weakly exogenous with respect to $\ln \left(H P_{t}\right)$, and that the cointegration and dynamic panel fixed-effects results are not subject to low power due to the violation of weak exogeneity. A further implication of the suggestion of the two absolute measures of inequality $\left(\ln \left(\operatorname{Var}_{t}\right)\right.$ and $\left.\ln \left(\operatorname{Top} 5 \$_{t}\right)\right)$ being weakly exogenous with respect to

\footnotetext{
${ }^{25}$ When both an intercept and trend are included in the model the trend term is not significant. This suggests that the trend term can be excluded from the long-run equation and that cointegrating equations including a trend should not be favoured. This is consistent with the model including both intercept and trend providing less support for cointegration than the model where the intercept is the only deterministic term and suggests that there are no omitted variables from the long-run equations that approximately follow a linear trend.
} 
$\ln \left(H P_{t}\right)$ is that there is uni-directional long-run causality from absolute inequality to $\ln \left(H P_{t}\right)$ and no reverse causality in the opposite direction.

\section{$<$ Table 5>}

The individual country probability values of t-tests for LRGNC based on time-series regressions (Table 6) confirm the above finding that for the majority of countries there is no evident violation of the weak exogeneity assumption. To be more precise, for nine of the 15 countries there is evidence that, in the long-run, $\ln \left(\operatorname{Var}_{t}\right)$ and/or $\ln \left(T o p 5 \$_{t}\right)$ Granger-causes $\ln \left(H P_{t}\right)$ and that $\ln \left(H P_{t}\right)$ does not Granger-cause $\ln \left(\operatorname{Var}_{t}\right)$. Moreover, it is important to note that for the six countries where the tests suggest a bi-directional long-run Granger-causality (CAN, IRE, NET, NEW, NOR, SPA), the hypothesis that $\ln \left(H P_{t}\right)$ Granger-causes $\ln \left(\operatorname{Var}_{t}\right)$ and/or $\ln \left(\operatorname{Top} 5 \$_{t}\right)$ in most cases is accepted only at the $10 \%$-level of significance. Hence, overall, the results indicate that the direction of causality is from absolute inequality to real house prices, and that the anomalies found may be due to small (time-series) sample effects and Type I errors.

The finding that the increase in house prices seemingly has not contributed substantially to the increase in inequality probably can be ascribed to the fact that in most countries rent income has risen only slowly. ${ }^{26}$ In the USA, for example, rents remained flat during a period of sustained increases in house prices (Sommer et al., 2011; 2013); which explains why Mikhed and Zemcik (2009) find that US rents and house prices were not cointegrated during 1980-2008. The same seems to be true for most of the other sample countries, given that the average house price to rent ratio nearly doubled during 1975-2010 (OECD, 2018). ${ }^{27}$

\section{$<$ Table $6>$}

\footnotetext{
${ }^{26}$ For EU countries the relatively low rent growth is explained mainly by strict rent controls (ECB, 2003).

${ }^{27}$ Please note that potential wealth or consumption effects (as discussed, for example, by Buiter (2010)) are not captured by the causality test on the grounds that the inequality variables used are based on income.
} 
Finally, we consider whether these results stay robust when the real short-term interest rate $\left(r_{t}\right)$ and the population size $\left(\ln \left(P o p_{t}\right)\right)$ are considered as additional covariates. First, we find that the interest rate series is unlikely to be cointegrated on its own with $\ln \left(H P_{t}\right)$ because in many cases it has a different order of integration. While $\ln \left(H P_{t}\right)$ is at least $\mathrm{I}(1)$ for the majority of countries, $r_{t}$ is found to be $\mathrm{I}(0)$ in nine and $\mathrm{I}(1)$ in the remaining six countries. ${ }^{28}$

That the real interest is $\mathrm{I}(0)$ for many countries is consistent with the Fisher hypothesis, (Malliaropulos (2000), Costantini and Lupi (2007), Omay and Yuksel (2015), Panopoulou and Pantelidis (2016)). However, $\left(r_{t}\right)$ can still potentially form part of the cointegrating relationship with $\ln \left(H P_{t}\right)$ when it is considered a covariate with another I(1) explanatory variable - see, for example, Pesaran et al. (2001) for a discussion of including I(0) and I(1) variables in an ADL model's equilibrium.

For all 15 countries the $\ln \left(P o p_{t}\right)$ series are indicted to be $I(2) .{ }^{29}$ While this suggests that $\ln \left(H P_{t}\right)$ and $\ln \left(\mathrm{Pop}_{t}\right)$ do not satisfy the necessary condition for cointegration we consider the possibility that any series indicated to be $I(1)$ is actually $I(1)$ around structural breaks and therefore can potentially cointegrate. This possibility is considered because of the well-known lack of power of unit root tests and to ensure that this theoretically postulated determinant of house prices is not neglected in our analysis. If the assumption that the necessary condition for cointegration being satisfied is incorrect this will likely be manifest in our tests rejecting cointegration and/or making the estimated cointegrating equations theoretically implausible.

Table 7 reports Westerlund's (2007) cointegration tests for trivariate regressions of $\ln \left(H P_{t}\right)$ on $I N E Q_{t}$ and $r_{t}$, and $\ln \left(H P_{t}\right)$ on $\ln \left(G D P p c_{t}\right)$ and $r_{t}$; and four-variable regressions of $\ln \left(H P_{t}\right)$ on $I N E Q_{t}, r_{t}$ and $\ln \left(P_{o p}\right)$, and $\ln \left(H P_{t}\right)$ on $\ln \left(G D P p c_{t}\right), r_{t}$ and $\ln \left(P o p_{t}\right)$. The results unambiguously indicate no evident cointegration for the models involving the two relative

\footnotetext{
${ }^{28}$ For the $\mathrm{n}=18$ sample, $r_{t}$ is $\mathrm{I}(0)$ for eleven countries and $\mathrm{I}(1)$ for the remaining seven countries.

29 The same is true for the $n=18$ sample.
} 
inequality variables (columns 5-6). With one exception, the same is true for the mean income variable (last column).

The only two variables of interest that demonstrate evidence favoring cointegration in the house price equation (with $r_{t}$ and/or $r_{t}$ and $\ln \left(P o p_{t}\right)$ ) are $\ln \left(\operatorname{Var}_{t}\right)$ and $\ln (T o p \$ t)$. Especially in the case of $\ln \left(\operatorname{Top} \$_{t}\right)$ this evidence is less robust than in the bivariate regressions but, potentially, this can be explained by the reduced efficiency due to increased covariates that raise (lower) the coefficient standard error (t-ratio) of the adjustment coefficient upon which the cointegration tests are based.

Nevertheless, although they should be treated with caution due to the small time-series dimension available and the leads and lags used, the results of Table 7 can be interpreted as being consistent and confirming of our bivariate cointegration analysis. That is to say, the presented evidence is suggestive that $\ln \left(\operatorname{Var}_{t}\right)$ and $\ln \left(\operatorname{Top} \$_{t}\right)$ form cointegrating equations with house prices in 15 OECD countries.

\section{$<$ Table $7>$}

\section{Conclusions}

Our results provide two novel insights. First, increasing income inequality contributed to the rise in real house prices in 15 OECD countries during the period 1975-2010. Second, the results are sensitive to the use of relative and absolute inequality measures.

To be more specific, the presented results indicate that the income variance and the market income of the Top 5\% form cointegrating equations with house prices (with a uni-directional causality from inequality to house prices), and that they are significant positive correlates of house prices. The short-term real interest rate also shows some evidence of being a significant long-run determinant, whereas relative inequality and mean income do not show any signs of 
long-run correlation or cointegration with house prices. The finding that the rise in mean income was not a main driver behind the long-run increase in house prices is surprising, but it is in line with some previous studies (e.g., Gallin, 2006; Mikhed and Zemcik, 2009; Knoll et al., 2017).

While it is important to note that the strong correlation between GDP per capita and absolute inequality makes it somewhat difficult to disentangle the effects of these two variables, overall, the results suggest that the surge in OECD house prices in part can be explained by a topincome-induced increase in housing demand, and that it is important to consider the interaction of rising mean income and its relative distribution when studying potential correlates of house prices.

This finding not only contributes to a growing literature that argues that the recent inequality increase in developed countries has important socio-economic effects (see e.g., OECD, 2015), but moreover suggests that the current focus on relative inequality measures is unduly restrictive and that future research should give more attention to alternative inequality measures like the ones presented in this article.

\section{REFERENCES}

Addison-Smyth, D., McQuinn, K. and O’Really, G. (2009). Modelling credit in the Irish mortgage market. The Economic and Social Review, 40(4): 371-392.

Agnello, L. and Schuknecht, L. (2011). Booms and busts in housing markets: Determinants and implications. Journal of Housing Economics, 20(3): 171-90.

Anderson, T.W. and Hsiao, C. (1982). Formulation and estimation of dynamic models using panel data. Journal of Econometrics, 18(1): 47-82.

Arellano, M. and Bond, S. (1991). Some Tests of Specification for Panel Data: Monte Carlo Evidence and an Application to Employment Equations. Review of Economic Studies, 58(2): 277-297.

Arellano, M. and Bover O. (1995). Another Look at the Instrumental Variables Estimation of Error Components Models. Journal of Econometrics, 68(1): 29-51.

Asteriou, D., and Hall S. G. (2016). Applied Econometrics. Palgrave Macmillan, $3^{\text {rd }}$ edition. 
Atkinson, A. B. and Brandolini, A. (2010). On analyzing the world distribution of income. World Bank Economic Review, 24(1): 1-37.

Bazillier, R. and Hericourt, J. (2017). The Circular Relationship between inequality, leverage, and financial crises. Journal of Economic Survey, 31(2): 463-496.

Blundell, R. and Bond, S. (1998). Initial Conditions and Moment Restrictions in Dynamic Panel Data Models. Journal of Econometrics, 87(1): 115-143.

Bonesmo Fredriksen, K. (2012). "Less Income Inequality and More Growth - Are they Compatible? Part 6. The Distribution of Wealth". OECD Economics Department Working Papers, No. 929.

Bordo, M.D. and Landon-Lane, J. (2013a). Does Expansionary Monetary Policy Cause Asset Price Booms; some historical and empirical evidence. NBER Working Paper, No. 19585.

Bordo, M.D. and Landon-Lane, J. (2013b). What Explains House Price Booms?: History and Empirical Evidence. NBER Working Paper, No. 19584.

Bruno, G. S. F. (2005a). Approximating the bias of the LSDV estimator for dynamic unbalanced panel data models. Economics Letters, 87(3): 361-366.

Bruno, G. S. F. (2005b). Estimation and inference in dynamic unbalanced panel-data models with a small number of individuals. The Stata Journal, 5(4): 473-500.

Buiter, W.H. (2010). Housing Wealth Isn’t Wealth. Economics, 4: 1-28.

Campbell, J.Y. and Cocco, J.F. (2007). How do house prices affect consumption? Evidence from micro data. Journal of Monetary Economics, 54(3): 591-621.

Case, K.E. and Shiller, R.J. (2003). Is There a Bubble in the Housing Market? Brookings Papers on Economic Activity, 34(2): 299-362.

Case, K.E., Quigley, J.M. and Shiller, R.J. (2005). Comparing Wealth Effects: The Stock Market versus the Housing Market. B.E. Journal of Macroeconomics, 5(1): 1-34.

Case, K.E., Quigley, J.M. and Shiller, R.J. (2013). Wealth Effects Revisited 1975-2012. Critical Finance Review, 2(1): 101-128.

Cerrato, M., Peretti C.D., Larsson R. and Sarantis, N. (2009). "A nonlinear panel unit root test under cross section dependence", Discussion Paper 2009-28, Department of Economics, University of Glasgow.

Cerrato, M., Peretti C.D., Larsson R. and Sarantis, N., (2011). “A Nonlinear Panel Unit Root Test under Cross Section Dependence", Scottish Institute for Research in Economics Discussion Papers, No. 2011-08.

Cesa-Bianchi, A., Cespedes, L.F. and Rebucci, A. (2015). Global Liquidity, House Prices, and the Macroeconomy: Evidence from Advanced and Emerging Economies. Journal of Money, Credit and Banking, 47(1): 301-335. 
Chakravarty, S.R. (2001). The variance as a subgroup decomposable measure of inequality. Social Indicators Research, 53(1): 79-95.

Chortareas, G. and Kapetanios G. (2009). Getting PPP right: Identifying mean-reverting real exchange rates in panels. Journal of Banking and Finance, 33: 390-404.

Collinson, P. (2015). "Average house price rises to 8.8 times local salary in England and Wales". The Guardian online, 6 August.

Costantini, M. and Lupi, C. (2007). An analysis of inflation and interest rates. New panel unit root results in the presence of structural breaks. Economics Letters, 95(3): 408-414.

Cowell, F., Karagiannaki, E. and McKnight, A. (2012). 'Accounting for Cross-Country Differences in Wealth Inequality'. LWS Working Paper Series, No. 13.

Dewilde, C. and Lancee, B. (2013). Income Inequality and Access to Housing in Europe. European Sociological Review, 29(6): 1189-1200.

Dokko, J., Doyle, B.M., Kiley, M.T., Kim, J., Sherlund, S., Sim, J., and van Den Heuvel, S. (2011). Monetary policy and the global housing bubble. Economic Policy, 26(4): 233-283.

Easterly, W. and Fischer, S. (2001). Inflation and the Poor. Journal of Money, Credit and Banking, 33(2): 160-178.

ECB (2003). Structural Factors in the EU Housing Market. Frankfurt: European Central Bank.

Gallin, J. (2006). The Long-Run Relationship between House Prices and Income: Evidence from Local Housing Markets. Real Estate Economics, 34(3): 417-438.

Gerdesmeier, D., Reimersz, H.-E. and Roffia, B. (2010). Asset Price Misalignments and the Role of Money and Credit. International Finance, 13(3): 377-407.

Goda, T. and Lysandrou, P. (2014). The Contribution of Wealth Concentration to the Subprime Crisis: A Quantitative Estimation. Cambridge Journal of Economics, 38(2): 301-27.

Goda, T. and Torres García, A. (2017). The Rising Tide of Absolute Global Income Inequality During 1850-2010: Is It Driven by Inequality Within or Between Countries?. Social Indicators Research, 130(3): 1051-1072.

Goda, T., Onaran, O. and Stockhammer, E. (2017). Income Inequality and Wealth Concentration in the Recent Crisis. Development and Change, 48(1): 3-27.

Goodhart, C. and Hofmann, B. (2008). House prices, money, credit, and the macroeconomy. Oxford Review of Economic Policy, 24(1): 180-205.

Gyourko, J., Mayer, C. and Sinai, T (2013). Superstar Cities. American Economic Journal: Economic Policy, 5(4): 167-99.

Hilbers, P., Hoffmaister, A.W., Banerji, A. and Shi, H. (2008). 'House Price Developments in Europe: A Comparison'. IMF Working Paper, No. 08/211.

Hryshko, D., Luengo-Prado, M.J. and Sørensen, B.E. (2010). House prices and risk sharing. Journal of Monetary Economics, 57(8): 975-987. 
Im, K. S., Pesaran, M. and Shin, Y. (2003). 'Testing for unit roots in heterogeneous panels', Journal of Econometrics, 115: 53-74.

Jenkins, S.P. (2015). World income inequality databases: an assessment of WIID and SWIID. Journal of Economic Inequality, 13(4): 629-671.

Jiménez, G, Mian, A., Peydró, J.-L. and Saurina, J. (2010). 'Local versus aggregate lending channels: the effects of securitization on corporate credit supply in Spain'. NBER Working Paper, No. 16595.

Jordà, O., Schularick, M. and Taylor, A.M. (2014). The Great Mortgaging: Housing Finance, Crises, and Business Cycles. NBER Working Paper, No. 20501.

Kim, K.-H. and Cho, M. (2010). Structural Changes, Housing Price Dynamics and Housing Affordability in Korea. Housing Studies, 25(6): 839-856.

Knoll, K., Schularick, M. and Steger, T.M. (2017). No Price Like Home: Global House Prices, 1870-2012. American Economic Review, 107(2): 331-351.

Krainer, J., Spiegel, M.M. and Yamori, N. (2010). Asset Price Persistence and Real Estate Market Illiquidity: Evidence from Japanese Land Values. Real Estate Economics, 38(2): 171-196.

Lysandrou, P. (2011a). Global Inequality as One of the Root Causes of the Financial Crisis: A Suggested Explanation. Economy and Society, 40(3): 323-44.

Lysandrou, P. (2011b) Global Inequality, Wealth Concentration and the Subprime Crisis: A Marxian Commodity Theory Analysis. Development and Change, 42(1): 183-208.

Määttänen, N. and Terviö, M. (2014). Income distribution and housing prices: An assignment model approach. Journal of Economic Theory, 151: 381-410.

Malliaropulos, D. (2000). A note on nonstationarity, structural breaks, and the Fisher effect. Journal of Banking and Finance, 24(5): 695-707.

Matlack, J.L. and Vigdor, J.L. (2008). Do rising tides lift all prices? Income inequality and housing affordability. Journal of Housing Economics, 17(3): 212-224.

McNown, R., Sam, C.Y. and Goh, S.K. (2018). Bootstrapping the Autoregressive Distributed Lag Test for Cointegration. Applied Economics, 50(3): 1509-1521.

Mian, A. and Amir S. (2010). The Great Recesion: Lessons from Microeconomic Data. American Economic Review, 100(2): 51-56.

Mian, A. and Amir, S. (2009). The Consequences of Mortgage Credit Expansion: Evidence from the U.S. Mortgage Default Crisis. Quarterly Journal of Economics, 124(4): 1449-1496.

Mian, A. and Sufi, A. (2015). House of Debt: How They (and You) Caused the Great Recession, and How We Can Prevent It from Happening Again. Chicago: University of Chicago Press.

Mian, A., Rao, K. and Sufi, A. (2013). Household Balance Sheets, Consumption, and the Economic Slump. Quarterly Journal of Economics, 128(4), 1687-1726. 
Mikhed, V. and Zemcik, P. (2009). Do house prices reflect fundamentals? Aggregate and panel data evidence. Journal of Housing Economics, 18(2): 140-149.

Nakajima, M. (2005). 'Rising Earnings Instability, Portfolio Choice and Housing Prices'. Mimeo, University of Illinois, Urbagna Champaign.

Nickell, S. (1981). Biases in dynamic models with fixed effects. Econometrica, 49(6): 14171426.

Nieto, F. (2007). 'The determinants of household credit in Spain'. Banco de España Working Paper, No. 716.

OECD (2015). In It Together: Why Less Inequality Benefits All. Paris: Organisation for Economic Co-operation and Development.

OECD (2018). OECD.Stat: Analytical house prices indicators. Retrieved at 19/07/2018 from https://stats.oecd.org.

Omay, T. and Yuksel, A. and Yuksel, A. (2015). An empirical examination of the generalized Fisher effect using cross-sectional correlation robust tests for panel cointegration. Journal of International Financial Markets, Institutions and Money, 35: 18-29.

Panopoulou, E. and Pantelidis, T. (2016). The Fisher effect in the presence of time-varying coefficients. Computational Statistics and Data Analysis, 100: 495-511.

Persyn, D. and Westerlund, J. (2008). Error Correction Based cointegration Tests for Panel Data. Stata Journal, 8(2): 232-241.

Pesaran, M. H. (2007). A simple panel unit root test in the presence of cross section dependence. Journal of Applied Econometrics, 22(2): 265-312.

Pesaran, M.H., Shin, Y., and Smith, R.J. (2001). Bounds Testing Approaches to the Analysis of Level Relationships. Journal of Applied Econometrics 16(3): 289-326.

Rajan, R.G. (2010). Fault Lines. How Hidden Fractures Still Threaten the World Economy. Princeton: Princeton University Press.

Ravallion, M. (2004). Competing concepts of inequality in the globalization debate. In Collins, S.M. and Graham, C. (Eds.), Brookings trade forum 2004. Globalization, poverty, and inequality. Washington: Brookings Institution Press, pp. 1-38.

Roodman, D. (2006). "How to Do xtabond2: An Introduction to 'Difference' and 'System' GMM in Stata", Center for Global Development Working Paper, No. 103.

Roodman, D. (2009). "How to do xtabond2: An introduction to difference and system GMM in Stata. Stata Journal, 9(1): 86-136.

Sá, F., Towbin, P. and Wieladek, T. (2014). Capital inflows, financial structure and housing booms. Journal of the European Economic Association, 12(2): 522-546.

Solt, F. (2015). On the assessment and use of cross-national income inequality datasets. Journal of Economic Inequality, 13(4): 683-691. 
Sommer, K., Sullivan, P. and Verbrugge, R. (2011). 'Run-up in the House Price-Rent Ratio: How Much Can Be Explained by Fundamentals?'. U.S. Bureau of Labor Statistics Working Paper, No. 411.

Sommer, K., Sullivan, P. and Verbrugge, R. (2013). The equilibrium effect of fundamentals on house prices and rents. Journal of Monetary Economics, 60(7): 854-870.

Stewart, C. (2011) 'A note on spurious significance in regressions involving $I(0)$ and $I(1)$ variables', Empirical Economics, 41(3): 565-571.

Stroebel, J. and Vavra, J. (2014). 'House Prices, Local Demand and Retail Prices'. NBER Working Paper, No. 20710.

Taylor, J.B. (2007). 'Housing and Monetary Policy'. NBER Working Paper, No. 13682.

van Treeck, T. (2014). Did Inequality Cause the U.S. Financial crisis?. Journal of Economic Surveys, 28(3): 421-48.

Westerlund, J. (2007). Testing for Error Correction in Panel Data. Oxford Bulletin of Economics and Statistics, 69(6): 709-748.

Zhang, F. (2016). Inequality and House Prices. University of Michigan Department of Economics, Job Market Paper. 
Table 1: Dynamic panel fixed-effects estimator regressions for $\ln \left(H P_{t}\right)$

\begin{tabular}{|c|c|c|c|c|}
\hline & $\ln ($ Var $)$ & $\ln (T o p 5 \$)$ & Gini & Top5\% \\
\hline$\Delta I N E Q_{t}$ & $\begin{array}{l}-0.046 \\
(-0.74)\end{array}$ & $\begin{array}{l}-0.143 \\
(-1.09)\end{array}$ & $\begin{array}{l}-0.430 \\
(-1.12)\end{array}$ & $\begin{array}{l}-0.758 \\
(-1.17)\end{array}$ \\
\hline$\Delta \ln (G D P p c)_{t}$ & $\begin{array}{c}1.253 * * * \\
(4.59)\end{array}$ & $\begin{array}{c}1.307 * * * \\
(4.78)\end{array}$ & $\begin{array}{c}1.163 * * * \\
(4.90)\end{array}$ & $\begin{array}{c}1.160 * * * \\
(4.90)\end{array}$ \\
\hline$\Delta \ln (P o p)_{t}$ & $\begin{array}{l}2.216 \\
(1.37)\end{array}$ & $\begin{array}{l}2.201 \\
(1.38)\end{array}$ & $\begin{array}{l}2.177 \\
(1.36)\end{array}$ & $\begin{array}{l}2.154 \\
(1.35)\end{array}$ \\
\hline$\Delta r_{t}$ & $\begin{array}{l}0.044 \\
(0.20)\end{array}$ & $\begin{array}{l}0.050 \\
(0.23)\end{array}$ & $\begin{array}{l}0.052 \\
(0.24)\end{array}$ & $\begin{array}{l}0.053 \\
(0.25)\end{array}$ \\
\hline$\Delta \ln (H P)_{t-1}$ & $\begin{array}{c}0.562 * * * \\
(12.68)\end{array}$ & $\begin{array}{c}0.557 * * * \\
(12.53)\end{array}$ & $\begin{array}{c}0.558 * * * \\
(12.53)\end{array}$ & $\begin{array}{c}0.556 * * * \\
(12.49)\end{array}$ \\
\hline$\Delta I N E Q_{t-1}$ & $\begin{array}{l}-0.020 \\
(-0.34)\end{array}$ & $\begin{array}{l}-0.032 \\
(-0.25)\end{array}$ & $\begin{array}{l}-0.098 \\
(-0.26)\end{array}$ & $\begin{array}{l}-0.171 \\
(-0.27)\end{array}$ \\
\hline$\Delta \ln (G D P p c)_{t-1}$ & $\begin{array}{l}-0.178 \\
(-0.66)\end{array}$ & $\begin{array}{l}-0.191 \\
(-0.71)\end{array}$ & $\begin{array}{l}-0.230 \\
(-0.94)\end{array}$ & $\begin{array}{l}-0.237 \\
(-0.96)\end{array}$ \\
\hline$\Delta \ln (P o p)_{t-1}$ & $\begin{array}{l}0.044 \\
(0.03)\end{array}$ & $\begin{array}{l}0.093 \\
(0.06)\end{array}$ & $\begin{array}{l}0.081 \\
(0.05)\end{array}$ & $\begin{array}{l}0.083 \\
(0.05)\end{array}$ \\
\hline$\Delta r_{t-1}$ & $\begin{array}{l}-0.206 \\
(-0.98)\end{array}$ & $\begin{array}{l}-0.209 \\
(-1.00)\end{array}$ & $\begin{array}{l}-0.206 \\
(-0.99)\end{array}$ & $\begin{array}{l}-0.204 \\
(-0.98)\end{array}$ \\
\hline $\ln (H P)_{t-1}$ & $\begin{array}{c}-0.077 * * * \\
(-2.70)\end{array}$ & $\begin{array}{c}-0.077 * * * \\
(-2.73)\end{array}$ & $\begin{array}{c}-0.077 * * * \\
(-2.72)\end{array}$ & $\begin{array}{c}-0.077 * * * \\
(-2.72)\end{array}$ \\
\hline$I N E Q_{t-1}$ & $\begin{array}{l}-0.005 \\
(-0.16)\end{array}$ & $\begin{array}{l}-0.026 \\
(-0.42)\end{array}$ & $\begin{array}{l}-0.068 \\
(-0.38)\end{array}$ & $\begin{array}{l}-0.100 \\
(-0.33)\end{array}$ \\
\hline $\ln (G D P p c)_{t-1}$ & $\begin{array}{l}0.083 \\
(1.09)\end{array}$ & $\begin{array}{l}0.104 \\
(1.25)\end{array}$ & $\begin{array}{l}0.077 \\
(1.58)\end{array}$ & $\begin{array}{l}0.077 \\
(1.59)\end{array}$ \\
\hline $\ln (P o p)_{t-1}$ & $\begin{array}{l}0.116 \\
(0.90)\end{array}$ & $\begin{array}{l}0.125 \\
(0.98)\end{array}$ & $\begin{array}{l}0.122 \\
(0.95)\end{array}$ & $\begin{array}{l}0.120 \\
(0.94)\end{array}$ \\
\hline$r_{t-1}$ & $\begin{array}{l}-0.201 \\
(-1.22)\end{array}$ & $\begin{array}{l}-0.187 \\
(-1.14)\end{array}$ & $\begin{array}{l}-0.190 \\
(-1.16)\end{array}$ & $\begin{array}{l}-0.190 \\
(-1.17)\end{array}$ \\
\hline
\end{tabular}

Table notes: The sample comprises 15 OECD countries (see Section 3.1.1 for details). The first column denotes the potential correlates of house prices that are considered in the regressions, while the first row clarifies the INEQ measure involved. T-ratios are given in parentheses and *, ** and *** denote rejection of the noncointegration null at the 10\%, 5\% and $1 \%$ levels, respectively. 
Table 2: Dynamic panel fixed-effects estimator regressions for $\ln \left(H P_{t}\right)$, considering multicollinearity issues

\begin{tabular}{|c|c|c|c|c|c|}
\hline & $\begin{array}{c}\boldsymbol{l n}(\boldsymbol{G D P p} \boldsymbol{P}) \\
\text { omitting } \\
I N E Q\end{array}$ & $\begin{array}{c}\ln (\text { Var }) \\
\text { omitting } \\
\ln (G D P p c)\end{array}$ & $\begin{array}{c}\ln (\boldsymbol{T o p} \mathbf{5} \$) \\
\text { omitting } \\
\ln (G D P p c)\end{array}$ & $\begin{array}{c}\text { Gini } \\
\text { omitting } \\
\ln (G D P p c)\end{array}$ & $\begin{array}{c}\text { Top5\% } \\
\text { omitting } \\
\ln (G D P p c)\end{array}$ \\
\hline$\triangle I N E Q_{t}$ & & $\begin{array}{l}0.090 * \\
(1.68)\end{array}$ & $\begin{array}{l}\text { 0.178* } \\
(1.60)\end{array}$ & $\begin{array}{l}-0.369 \\
(-0.79)\end{array}$ & $\begin{array}{l}-0.667 \\
(-0.85)\end{array}$ \\
\hline$\Delta \ln (G D P p c)_{t}$ & $\begin{array}{l}1.162 * * * \\
(4.71)\end{array}$ & & & & \\
\hline$\Delta \ln (\boldsymbol{P o p})_{t}$ & $\begin{array}{l}2.149 \\
(1.30)\end{array}$ & $\begin{array}{l}1.381 \\
(0.84)\end{array}$ & $\begin{array}{l}1.494 \\
(0.91)\end{array}$ & $\begin{array}{l}1.954 \\
(1.02)\end{array}$ & $\begin{array}{l}1.944 \\
(1.02)\end{array}$ \\
\hline$\Delta r_{t}$ & $\begin{array}{l}0.025 \\
(0.11)\end{array}$ & $\begin{array}{l}-0.037 \\
(-0.17)\end{array}$ & $\begin{array}{l}-0.039 \\
(-0.18)\end{array}$ & $\begin{array}{l}-0.054 \\
(-0.21)\end{array}$ & $\begin{array}{l}-0.050 \\
(-0.19)\end{array}$ \\
\hline$\Delta \ln (H P)_{t-1}$ & $\begin{array}{l}0.568 * * * \\
(12.92)\end{array}$ & $\begin{array}{l}\text { 0.684*** } \\
(14.82)\end{array}$ & $\begin{array}{l}0.684 * * * \\
(14.78)\end{array}$ & $\begin{array}{l}\text { 0.679*** } \\
(15.43)\end{array}$ & $\begin{array}{l}\mathbf{0 . 6 7 6 * * * *} \\
(\mathbf{1 5 . 4 0 )}\end{array}$ \\
\hline$\Delta I N E Q_{t-1}$ & & $\begin{array}{l}-0.039 \\
(-0.68) \\
\end{array}$ & $\begin{array}{l}-0.077 \\
(-0.65) \\
\end{array}$ & $\begin{array}{l}-0.115 \\
(-0.25) \\
\end{array}$ & $\begin{array}{l}-0.196 \\
(-0.25) \\
\end{array}$ \\
\hline$\Delta \ln (G D P p c)_{t-1}$ & $\begin{array}{l}-0.181 \\
(-0.72)\end{array}$ & & & & \\
\hline$\Delta \ln (P o p)_{t-1}$ & $\begin{array}{l}0.045 \\
(0.03) \\
\end{array}$ & $\begin{array}{l}-0.516 \\
(-0.31) \\
\end{array}$ & $\begin{array}{l}-0.604 \\
(-0.36) \\
\end{array}$ & $\begin{array}{l}-0.647 \\
(-0.33) \\
\end{array}$ & $\begin{array}{l}-0.618 \\
(-0.32) \\
\end{array}$ \\
\hline$\Delta r_{t-1}$ & $\begin{array}{l}-0.210 \\
(-0.99)\end{array}$ & $\begin{array}{l}-0.284 \\
(-1.28)\end{array}$ & $\begin{array}{l}-0.294 \\
(-1.34)\end{array}$ & $\begin{array}{l}-0.410 * \\
(-1.65)\end{array}$ & $\begin{array}{l}-0.406 \\
(-1.63)\end{array}$ \\
\hline $\ln (H P)_{t-1}$ & $\begin{array}{l}-0.079 * * * \\
(-2.72)\end{array}$ & $\begin{array}{l}-0.105 * * * \\
(-3.97)\end{array}$ & $\begin{array}{l}-0.104 * * * \\
(-3.96)\end{array}$ & $\begin{array}{l}-0.072 * * \\
(-2.50)\end{array}$ & $\begin{array}{l}-0.072 * * \\
(-2.50)\end{array}$ \\
\hline$I N E Q_{t-1}$ & & $\begin{array}{l}\text { 0.038* } \\
(\mathbf{1 . 8 4})\end{array}$ & $\begin{array}{l}\text { 0.072* } \\
(1.74)\end{array}$ & $\begin{array}{l}0.091 \\
(0.40)\end{array}$ & $\begin{array}{l}0.183 \\
(0.47)\end{array}$ \\
\hline $\ln (G D P p c)_{t-1}$ & $\begin{array}{c}0.070 \\
(1.40) \\
\end{array}$ & & & & \\
\hline $\ln (P o p)_{t-1}$ & $\begin{array}{c}0.125 \\
(1.04) \\
\end{array}$ & $\begin{array}{l}0.093 \\
(0.65) \\
\end{array}$ & $\begin{array}{l}0.105 \\
(0.75) \\
\end{array}$ & $\begin{array}{l}0.207 \\
(1.42) \\
\end{array}$ & $\begin{array}{l}0.203 \\
(1.40) \\
\end{array}$ \\
\hline$r_{t-1}$ & $\begin{array}{l}-0.228 \\
(-1.40)\end{array}$ & $\begin{array}{l}-0.342 * \\
(-1.94)\end{array}$ & $\begin{array}{l}-0.333 * \\
(-1.91)\end{array}$ & $\begin{array}{l}-0.272 \\
(-1.31)\end{array}$ & $\begin{array}{l}-0.271 \\
(-1.31)\end{array}$ \\
\hline
\end{tabular}

Table notes: See notes to Table 1, except the first row denotes the measure involved and the variable omitted in the regression. 
Table 3: Robust p-values for Westerlund's (2007) panel cointegration tests of $\ln \left(H P_{t}\right)$ on $I N E Q_{t}$ or $\ln \left(G D P p c_{t}\right)$

\begin{tabular}{|c|c|c|c|c|c|c|c|c|c|c|}
\hline & \multicolumn{2}{|c|}{$\ln \left(\operatorname{Var}_{t}\right)$} & \multicolumn{2}{|c|}{$\ln \left(\operatorname{Top} \$_{t}\right)$} & \multicolumn{2}{|c|}{$\operatorname{Gini}_{t}$} & \multicolumn{2}{|c|}{ Top5\% ${ }_{t}$} & \multicolumn{2}{|c|}{$\ln \left(G D P p c_{t}\right)$} \\
\hline & Int & Trend & Int & Trend & Int & Trend & Int & Trend & Int & Trend \\
\hline$G_{\tau}$ & $0.001^{* * * *}$ & $0.013^{* *}$ & $0.005^{* * *}$ & $0.053^{*}$ & 0.964 & 0.32 & 0.981 & 0.330 & 0.434 & 0.980 \\
\hline$G_{\alpha}$ & $\mathbf{0}$ & & 0.03 & 0.114 & 0.8 & 0.133 & 92 & 0 & 0.186 & 0.700 \\
\hline$P_{\tau}$ & $0.000^{* * *}$ & $0.014^{* *}$ & $0.001^{* * * *}$ & 0.059* & 0.424 & 0.174 & 0.445 & 0.159 & 0.205 & 0.868 \\
\hline$P_{\alpha}$ & $0.001^{* * *}$ & $0.084^{*}$ & $0.004^{* * *}$ & $0.089^{*}$ & 0.413 & 0.308 & 0.409 & 0.240 & $0.011^{* *}$ & 0.753 \\
\hline Leads & 1.27 & 1.47 & 7 & 1.60 & 1.33 & 1.20 & 1.33 & 1.20 & 1.60 & 1.40 \\
\hline Lags & 1.13 & 1.27 & 1.13 & 1.33 & 1.07 & 1.07 & 1.13 & 1.07 & 1.27 & 1.27 \\
\hline
\end{tabular}

Table notes: The first row denotes the measure involved in the potential cointegrating equation with $\ln \left(H P_{t}\right)$ as the dependent variable. The second row specifies the deterministic terms included in the cointegration equation as Int when only an intercept is included and Trend when both an intercept and trend are included. $G_{\tau}$ and $G_{\alpha}$ denote the tests when the alternative hypothesis is that there is cointegration for at least one country in the panel. $P_{\tau}$ and $P_{\alpha}$ denote the tests when the alternative hypothesis is that there is cointegration for all countries in the panel. All four tests are based on either OLS or heteroscedasticity and autocorrelation consistent (HAC) coefficient standard errors, respectively. The average number of leads and lags (selected with the AIC) used in the countries' error-correction models are specified in the rows labelled Leads and Lags, respectively. A maximum of 3 leads and lags are allowed. *,**and *** denote rejection of the non-cointegration null at the 10\%, 5\% and 1\% levels, respectively.

Table 4: Estimated panel long-run relationship and short-run adjustment for $\ln \left(H P_{t}\right)$

\begin{tabular}{|c|c|c|c|c|}
\hline \multirow{2}{*}{ Int } & \multicolumn{2}{|c|}{$\ln \left(\right.$ Var $\left._{\boldsymbol{t}}\right)$} & \multicolumn{2}{c|}{$\ln \left(\right.$ Top $\left._{\boldsymbol{t}}\right)$} \\
& Int & Trend & Int & Trend \\
\hline \multirow{2}{*}{ Intercept } & $\mathbf{0 . 4 9 7}_{t}^{* * * *}$ & 0.229 & $\mathbf{1 . 0 0 0}^{* * * *}$ & -0.014 \\
& $(6.49)$ & $(0.66)$ & $(6.71)$ & $(-0.02)$ \\
\hline \multirow{2}{*}{ Trend } & $-5.618^{* * *}$ & -14.802 & $-7.718^{* * * *}$ & -41.924 \\
& $(-3.71)$ & $(-0.28)$ & $(-4.35)$ & $(-1.04)$ \\
\hline \multirow{2}{*}{ Adjustment } & & 0.007 & & 0.023 \\
& & $(0.28)$ & & $(0.96)$ \\
& $-0.169^{* * *}$ & $-0.266^{* * *}$ & $-0.165^{* * *}$ & $-0.255^{* * *}$ \\
& $(-5.86)$ & $(-5.69)$ & $(-5.77)$ & $(-7.23)$ \\
\hline
\end{tabular}

Table notes: See notes to Table 3. The estimated long-run coefficients, with t-ratios given in parentheses, are reported for the two inequality measures that are cointegrated with $\ln \left(H P_{t}\right)$, where $\ln \left(H P_{t}\right)$ is the dependent variable. 
Table 5: Robust p-values for Westerlund's (2007) panel cointegration tests of $I N E Q_{t}$ or $\ln \left(G D P p c_{t}\right)$ on $\ln \left(H P_{t}\right)$

\begin{tabular}{|c|c|c|c|c|c|c|c|c|c|c|}
\hline & \multicolumn{2}{|c|}{$\ln \left(\operatorname{Var}_{t}\right)$} & \multicolumn{2}{|c|}{$\ln \left(\operatorname{Top}_{5} \$_{t}\right)$} & \multicolumn{2}{|c|}{$\operatorname{Gini}_{t}$} & \multicolumn{2}{|c|}{ Top5\% ${ }_{t}$} & \multicolumn{2}{|c|}{$\ln \left(G D P p c_{t}\right)$} \\
\hline & Int & Trend & Int & Trend & Int & Trend & Int & Trend & Int & Trend \\
\hline$G_{\tau}$ & 1.000 & 0.42 & 1.000 & 0.325 & 0.550 & 0.140 & 0.556 & 0.251 & 1.000 & 0.616 \\
\hline$G_{\alpha}$ & 1.000 & 0 & 1.000 & 0.193 & 0.811 & 0.593 & .82 & 0.677 & 1.000 & 0.866 \\
\hline$P_{\tau}$ & 0.984 & 0.771 & 0.973 & 0.719 & 0.435 & 0.430 & 0.461 & 0.439 & 0.971 & 0.995 \\
\hline$P_{\alpha}$ & 0.981 & 0.705 & 0.971 & 0.666 & 0.413 & 0.520 & 0.459 & 0.547 & 0.976 & 0.980 \\
\hline Leads & 1.47 & 1 & 1.20 & 27 & 1.07 & 1.00 & 1.07 & 1.00 & 1.07 & 1.60 \\
\hline Lags & 0.87 & 0.47 & 0.33 & 0.47 & 0.53 & 0.47 & 0.33 & 0.33 & 0.33 & 0.73 \\
\hline
\end{tabular}

Table notes: See notes to Table 3 except the first row denotes the inequality measure that is the dependent variable in the potential cointegrating equation with $\ln \left(H P_{t}\right)$ as the regressor.

Table 6: Time-series long-run GNC tests

\begin{tabular}{|c|c|c|c|c|c|c|}
\hline & \multicolumn{3}{|c|}{$\ln \left(\operatorname{Var}_{t}\right)$} & \multicolumn{3}{|c|}{$\ln \left(\operatorname{Top} 5 \$_{t}\right)$} \\
\hline & Lag & $\begin{array}{l}I N E Q_{t} \text { to } \\
\ln \left(H P_{t}\right)\end{array}$ & $\begin{array}{l}\ln \left(H P_{t}\right) \text { to } \\
I N E Q_{t}\end{array}$ & Lag & $\begin{array}{l}I N E Q_{t} \text { to } \\
\ln \left(H P_{t}\right)\end{array}$ & $\begin{array}{l}\ln \left(H P_{t}\right) \text { to } \\
I N E Q_{t}\end{array}$ \\
\hline AUS & 2 & $0.033 * *$ & 0.142 & 3 & $0.072^{*}$ & 0.438 \\
\hline BEL & 1 & $0.007 * * *$ & 0.425 & 1 & $0.007 * * *$ & 0.270 \\
\hline CAN & 3 & $0.002 * * *$ & $0.033^{* *}$ & 3 & $0.001 * * *$ & $0.066^{*}$ \\
\hline DEN & 1 & $0.014 * *$ & 0.987 & 1 & $0.013^{* *}$ & 0.850 \\
\hline FIN & 1 & $0.003 * * *$ & 0.805 & 1 & $0.003 * * *$ & 0.628 \\
\hline FRA & 1 & $0.008 * * *$ & 0.445 & 1 & $0.011^{* *}$ & 0.479 \\
\hline IRE & 2 & $0.058^{*}$ & $0.075^{*}$ & 2 & $0.059^{*}$ & $0.062 *$ \\
\hline ITA & 2 & $0.000 * * *$ & 0.644 & 2 & $0.000 * * *$ & 0.632 \\
\hline NET & 1 & $0.006 * * *$ & $0.082 *$ & 1 & $0.003 * * *$ & 0.105 \\
\hline NEW & 1 & $0.013 * *$ & $0.009 * * *$ & 1 & $0.023 * *$ & $0.003 * * *$ \\
\hline NOR & 1 & $0.015^{* *}$ & $0.083^{*}$ & 1 & $0.017 * *$ & $0.050^{*}$ \\
\hline SPA & 1 & 0.112 & $0.050^{*}$ & 1 & $0.079^{*}$ & $0.046 * *$ \\
\hline SWE & 1 & $0.003 * * *$ & 0.470 & 3 & 0.139 & 0.840 \\
\hline UKD & 1 & $0.021 * *$ & 0.438 & 1 & $0.020 * *$ & 0.539 \\
\hline USA & 3 & $0.014 * *$ & 0.982 & 3 & $0.008 * * *$ & 0.804 \\
\hline
\end{tabular}

Table notes: The probability value of a t-test on the error-correction term are reported. Lag denotes the VAR lag length chosen according to AIC criterion. INEQ $Q_{t}$ to $\ln \left(H P_{t}\right)$ refers to tests of the respective measure of inequality (reported in the top row) Granger-causing $\ln \left(H P_{t}\right)$, while $\ln \left(H P_{t}\right)$ to $I N E Q_{t}$ refers to tests of $\ln \left(H P_{t}\right)$ Grangercausing inequality. 
Table 7: Robust p-values for Westerlund's (2007) test of $\ln \left(H P_{t}\right)$ on $I N E Q_{t}$ or $\ln \left(G D P_{t}\right)$, considering $r_{t}$ and $\ln (P o p)_{t}$ as additional covariates

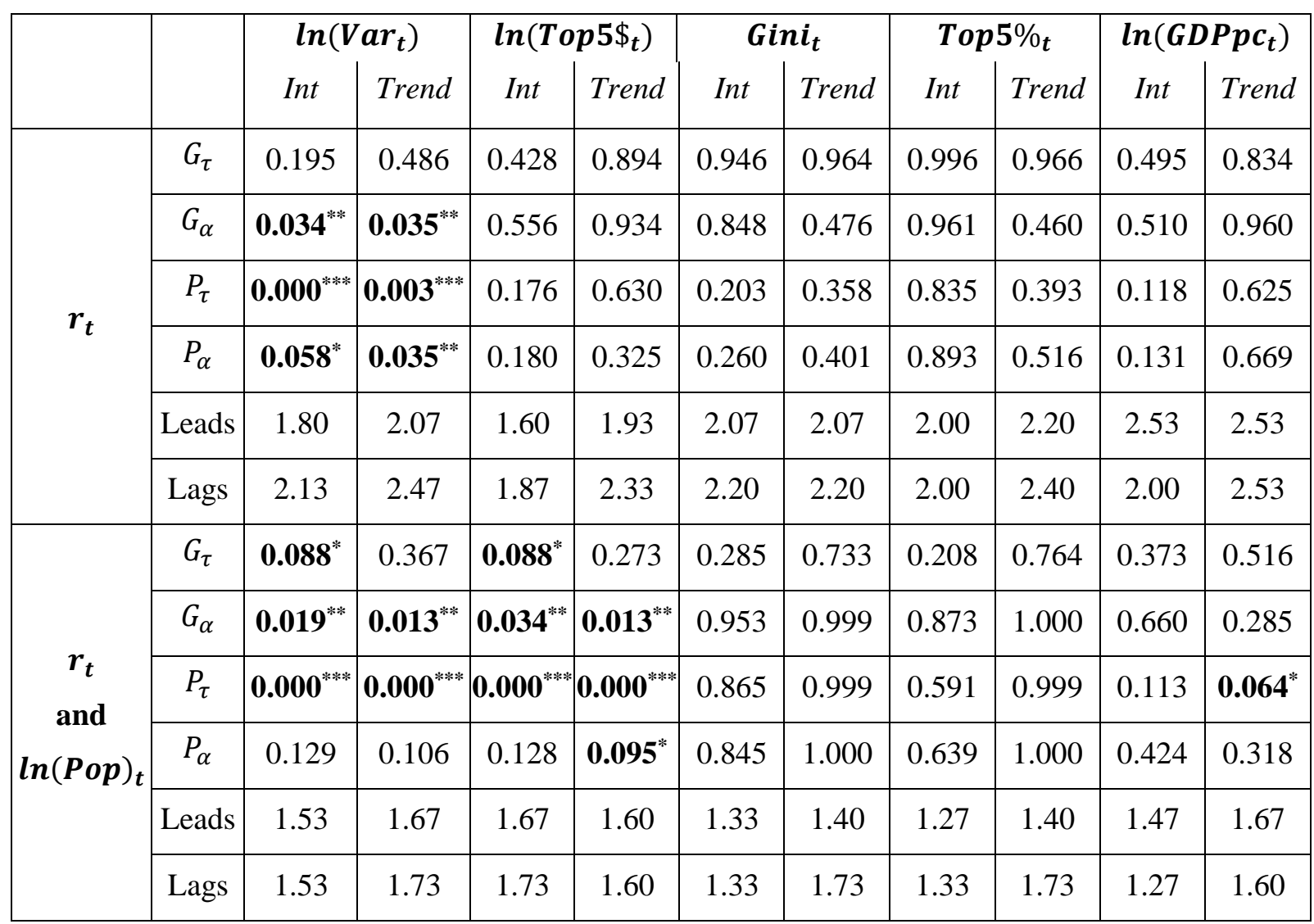

Table notes: See notes to Table 3, except the first column denotes the additional covariates involved in the potential cointegrating equations; namely $r_{t}$ in the three variate models, and $r_{t}$ and $\ln (\text { Pop })_{t}$ in the four variable models. 
Figure 1: Absolute inequality: the interaction between relative income distribution and mean income

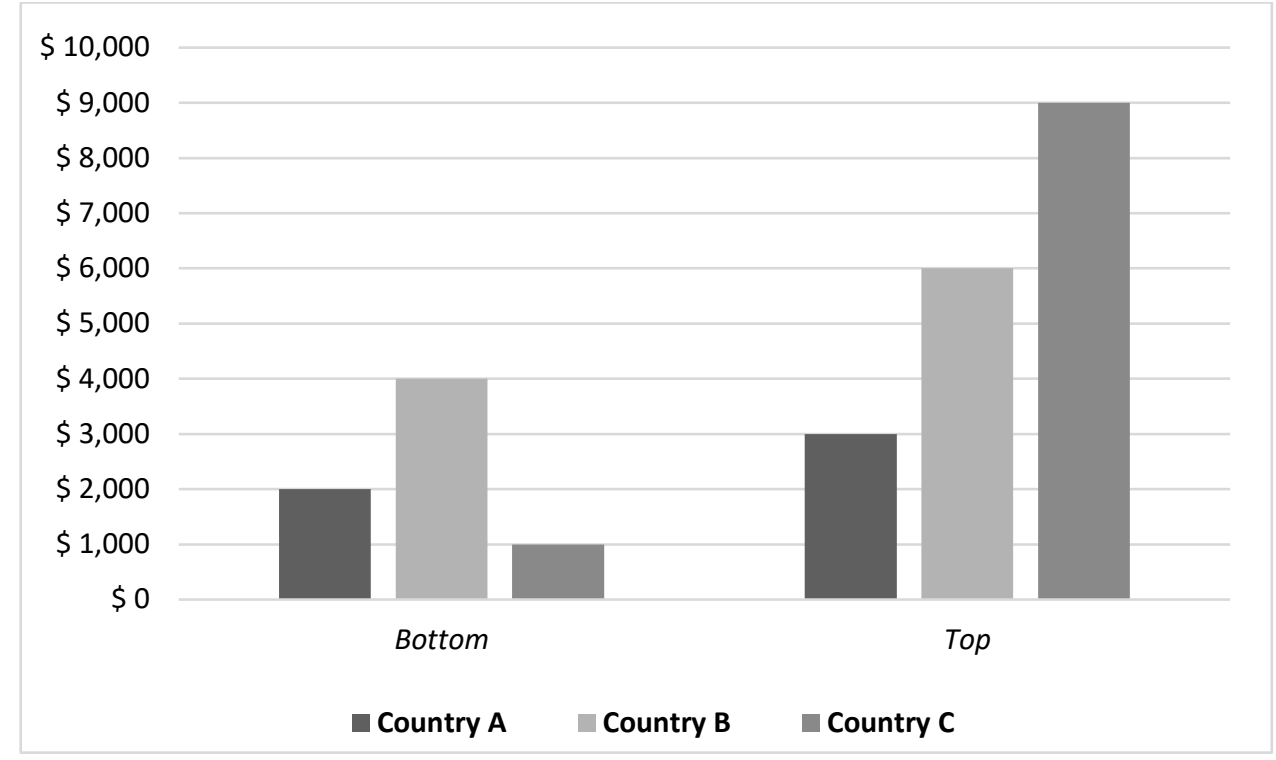

Note: This graph shows the income of the bottom and top earners of three fictitious countries. The countries differ in their relative income distribution (top income share) and/or mean income. The mean income of $A$ is $\$ 5,000$, while that of $B$ and $C$ is $\$ 10,000$. The top income share of $A$ and $B$ is $60 \%$, whereas that of $C$ is $90 \%$. 
Figure 2: Real house prices and absolute inequality in OECD countries, 1975-2010
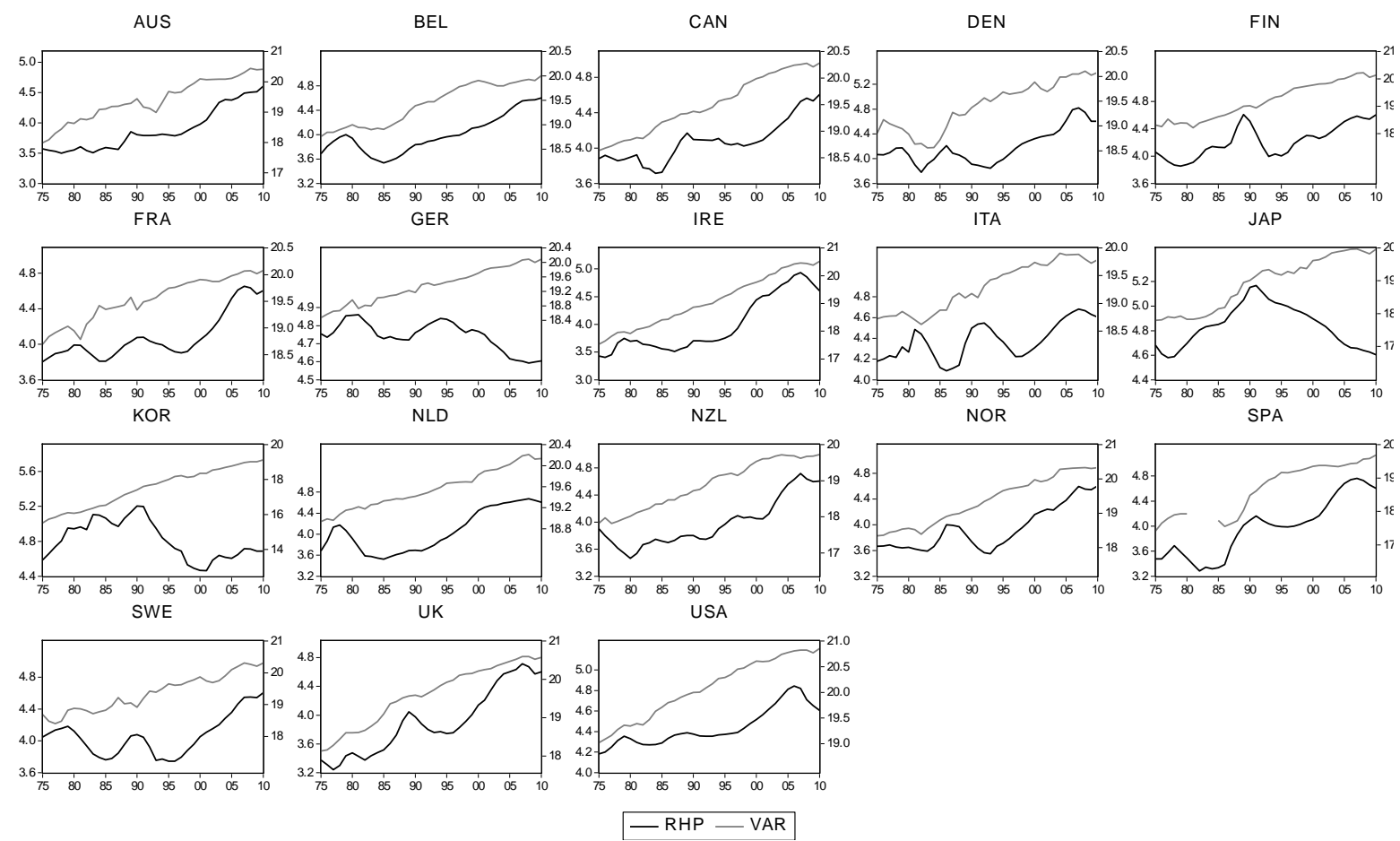

Note: The graphs show the evolution of the logarithm of real house prices (RHP, left axis) and the logarithm of the income variance (VAR, right axis) in 18 selected OECD countries during the period 1975-2010. 
Figure 3: Real house prices and relative inequality in OECD countries, 1975-2010
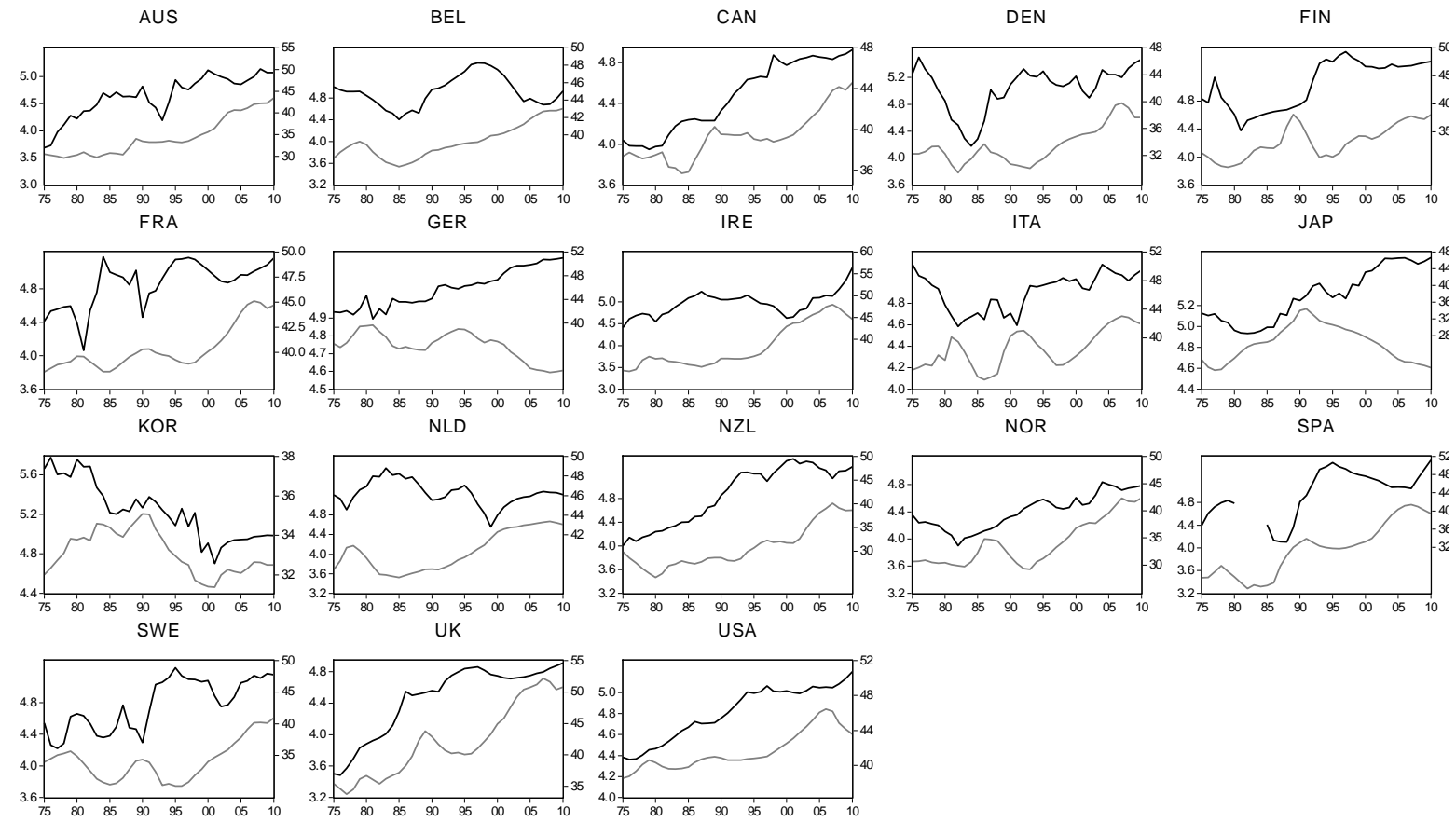

$$
-\mathrm{GINI}-\mathrm{RHP}
$$

Note: The graphs show the evolution of the logarithm of real house prices (RHP, left axis) and the Gini coefficient (Gini, right axis) in 18 selected OECD countries during the period 1975-2010. 


\section{APPENDIX}

Table A1: Correlation matrix of variables

\begin{tabular}{|c|c|c|c|c|c|c|c|c|}
\hline & $\ln (H P)$ & $\ln ($ Var $)$ & $\ln (\operatorname{Top} 5 \$)$ & Gini & Top5\% & $\ln (G D P p c)$ & $r$ & $\ln (\mathrm{Pop})$ \\
\hline $\ln (H P)$ & 1 & & & & & & & \\
\hline $\ln ($ Var $)$ & 0.726 & 1 & & & & & & \\
\hline $\ln (\operatorname{Top} 5 \$)$ & 0.652 & 0.922 & 1 & & & & & \\
\hline Gini & 0.406 & 0.681 & 0.572 & 1 & & & & \\
\hline Tор5\% & 0.399 & 0.675 & 0.567 & 0.997 & 1 & & & \\
\hline $\ln (G D P p c)$ & 0.535 & 0.740 & 0.866 & 0.135 & 0.127 & 1 & & \\
\hline$r$ & -0.103 & 0.081 & 0.102 & 0.092 & 0.082 & 0.110 & 1 & \\
\hline $\ln ($ Pop $)$ & 0.226 & 0.284 & 0.041 & 0.312 & 0.312 & -0.132 & -0.074 & 1 \\
\hline
\end{tabular}

\section{$\underline{\text { Unit Root Test procedure and results }}$}

To establish the (non-)stationarity of the data the unit root tests of Pesaran (2007) and Cerrato et al. $(2009,2011)$ are used. Pesaran's (2007) test assumes linear adjustment, can deal with cross-sectional dependence and is based upon the following time-series regression estimated for each $i$ :

$$
\Delta y_{i, t}=a_{i}^{P}+\alpha_{i}^{P} t+b_{i}^{P} y_{i, t-1}+c_{i, 0}^{P} \bar{y}_{t-1}+\sum_{j=1}^{p_{i}} c_{i, j}^{P} \Delta y_{i, t}+\sum_{j=0}^{p_{i}} d_{i, j}^{P} \Delta \bar{y}_{t-j}+u_{i, t}^{P}
$$

where, $i=1,2, \ldots, N ; t=1,2, \ldots, T, \Delta \bar{y}_{t}=\frac{1}{N} \sum_{i=1}^{N} y_{i, t}$ and $\bar{y}_{t-1}=\frac{1}{N} \sum_{i=1}^{N} y_{i, t-1}$.

The null hypothesis is that there is a unit root for all cross-sectional units, $b_{i}^{P}=0 \forall i$ while the alternative is that $y_{i, t}$ is stationary for at least one cross-section, $b_{i}^{P}<0$ for at least one $i$. The CADF statistic for each cross-section is the ordinary least squares (OLS) t-ratio corresponding to $b_{i}^{P}$, denoted $t_{i}^{P}(N, T)=\frac{\hat{b}_{i}^{P}}{S_{\hat{b}_{i}^{P}}}$. The panel test-statistic, CIPS, is:

$$
\text { CIPS }=\frac{1}{N} \sum_{i=1}^{N} t_{i}^{P}(N, T)
$$


The version of the test that we use, following the scheme given in Pesaran (2007) and denoted $t_{i}^{P^{*}}(N, T)$, is:

$$
\operatorname{CIPS}^{*}=\frac{1}{N} \sum_{i=1}^{N} t_{i}^{P^{*}}(N, T)
$$

Cerrato et al.'s $(2009,2011)$ heterogeneous nonlinear panel unit root tests involves estimating the following nonlinear auxiliary regression:

$$
\Delta y_{i, t}=a_{i}^{C}+\alpha_{i}^{C} t+b_{i}^{C} y_{i, t-1}^{3}+c_{i, 0}^{C} \overline{y_{t-1}^{3}}+\sum_{j=1}^{p_{i}} c_{i, j}^{C} \Delta y_{i, t}+\sum_{j=0}^{p_{i}} d_{i, j}^{C} \Delta \bar{y}_{t-j}+u_{i, t}^{C}
$$

where, $\overline{y_{t-1}^{3}}=\frac{1}{N} \sum_{i=1}^{N} y_{i, t-1}^{3}$. A time trend, $t$, is included following Cerrato et al. (2013) and the lag length, $p_{i}$, can be determined using information criteria.

The null hypothesis is $b_{i}^{C}=0 \forall i$, while the alternative is $b_{i}^{C}<0$ for at least one $i$. The tratios for each cross-section, denoted $t_{i}^{C}(N, T)=\frac{\hat{b}_{i}^{C}}{s_{\widehat{b}_{i}^{C}}^{C}}$, where $\hat{b}_{i}^{C}$ is the OLS estimate of $b_{i}^{C}$ and $s_{\hat{b}_{i}^{C}}$ is the corresponding OLS coefficient standard error, are used to calculate the panel teststatistic, thus:

$$
\bar{t}(N, T)=\frac{1}{N} \sum_{i=1}^{N} t_{i}^{C}(N, T)
$$

If the test-statistic is not more negative than the critical value, reported in Cerrato et al. (2009 and 2011), the null hypothesis cannot be rejected. Simulations indicate that this test has superior size and power than Pesaran's (2007) test when the data generating process is nonlinear.

For both panel unit root tests, the sequential panel selection method (SPSM), proposed by Chortareas and Kapetanios (2009), is applied to identify which cross-sections (countries) are stationary and which are nonstationary ${ }^{30}$. The null hypothesis is that all countries' series are $\mathrm{I}(1)$ and the alternative is that at least one country's series is $\mathrm{I}(0)$.

\footnotetext{
${ }^{30}$ Chortareas and Kapetanios (2009) apply the SPSM procedure to the Im et al. (2003) panel unit root test that does not account for cross-sectional dependence.
} 
The SPSM essentially involves applying the panel unit root test to all $N$ countries. For illustration we discuss the SPSM using the Cerrato et al.'s $(2009,2011)$ test although a similar procedure is also applied to the Pearan (2007) method. The Cerrato et al. $(2009,2011)$ teststatistic for all $\mathrm{N}$ countries is denoted $\bar{t}(N, T)$, and if the null cannot be rejected the procedure stops and all countries' series are I(1). However, if the null hypothesis is rejected at least one country's series is $\mathrm{I}(0)$ and we exclude the country that rejects the $\mathrm{I}(1)$ null the most, which is the one that has the smallest (most negative) individual country test-statistic, $\min \left\{t_{i}^{C}(N, T)\right\}$. The panel unit root test-statistic is calculated for the remaining $N-1$ countries, denoted $\bar{t}(N-1, T)$. The test is repeated for the remaining countries and the process continues until the panel unit root test cannot reject the null. All countries' series included in the last test are I(1) and all countries' series excluded from the last test are $\mathrm{I}(0)$.

To finally determine which series is stationary, trend-stationary or nonstationary we use the following procedure: if the unit root null is rejected using the test including only an intercept as a deterministic term the series is stationary. However, if the null is not rejected, the unit root test including both an intercept and trend is considered. If the null of this test is rejected the series is trend stationary, whereas if the null is not rejected the series has a unit root. ${ }^{31}$

Table A2 reports Pesaran's (2007) panel unit root test using the SPSM procedure applied to $\ln \left(H P_{t}\right), G I N I_{t}, T o p 5 \%_{t}, \ln \left(V A R_{t}\right), \ln \left(T o p 5 \$_{t}\right), \ln \left(G D P p c_{t}\right), \ln \left(P_{o p}\right)$ and $r_{t}$. The null hypothesis that all 18 countries' series in the panel are $I(1)$ cannot be rejected for all variables, except $r_{t}$, regardless of the deterministic specification of the test equations. In the case of $r_{t}, 7$ countries' series are $I(0)$ around a constant mean (BEL, CAN, ITA, KOR, NET, SPA and

\footnotetext{
${ }^{31}$ We only identify a series as trend stationary when the null of $\mathrm{I}(1)$ is being tested and not when the null is for an I(2) process because the latter involves a test on the differenced series and differencing should remove any (linear) trend in a series. Any structural breaks in the differenced series are likely to be mean shifts rather than changing slopes in trend.
} 
SWE), no countries' series are trend stationary and the 11 remaining countries' series are at least $I(1)$.

Table A2: Pesaran's (2007) panel unit root test applied to levels data with the SPSM procedure

\begin{tabular}{|c|c|c|c|c|c|}
\hline & & \multicolumn{2}{|c|}{ Intercept only } & \multicolumn{2}{|c|}{ Intercept and trend } \\
\hline Variable & $\mathbf{N}$ & Statistic & $5 \%$ critical & Statistic & $5 \%$ critical \\
\hline $\ln \left(H P_{t}\right)$ & 18 & -2.563 & -3.336 & -2.780 & -3.857 \\
\hline $\mathrm{GINI}_{t}$ & 18 & -2.530 & -3.335 & -3.064 & -3.855 \\
\hline Top $5 \%_{t}$ & 18 & -2.491 & -3.335 & -2.987 & -3.855 \\
\hline $\ln \left(V A R_{t}\right)$ & 18 & -2.720 & -3.334 & -2.790 & -3.855 \\
\hline $\ln \left(\operatorname{Top}_{5} \$_{t}\right)$ & 18 & -2.520 & -3.334 & -2.634 & -3.855 \\
\hline $\ln \left(G D P p c_{t}\right)$ & 18 & -2.312 & -3.335 & -2.411 & -3.855 \\
\hline $\ln \left(\mathrm{Pop}_{t}\right)$ & 18 & -1.657 & -3.338 & -1.682 & -3.860 \\
\hline Country excluded & \multicolumn{5}{|c|}{ Variable: $r_{t}$} \\
\hline SPA/SPA & 18 & $-3.979^{* *}$ & -3.335 & $-4.298^{* *}$ & -3.857 \\
\hline SWE/CAN & 17 & $-3.895^{* *}$ & -3.339 & $-4.201^{* *}$ & -3.858 \\
\hline CAN/BEL & 16 & $-3.785^{* *}$ & -3.344 & $-4.060^{* *}$ & -3.860 \\
\hline KOR/SWE & 15 & $-3.597^{* *}$ & -3.347 & $-3.878^{* *}$ & -3.861 \\
\hline ITA/ITA & 14 & $-3.579^{* *}$ & -3.347 & $-3.860^{* *}$ & -3.859 \\
\hline BEL/None & 13 & $-3.502^{* *}$ & -3.346 & -3.842 & -3.858 \\
\hline NET/None & 12 & $-3.362^{* *}$ & -3.345 & & \\
\hline None/None & 11 & -3.227 & -3.344 & & \\
\hline
\end{tabular}

Table notes. The column headed Variable indicates the variable that the tests are applied to and the column headed $N$ denotes the number of countries included in the panel unit root tests. The tests are applied with two sets of deterministic terms being only an intercept (reported in the column headed Intercept only) and an intercept and trend (reported in the column headed Intercept and trend). The truncated panel unit root test-statistics (CIPS) are reported in the columns headed Statistic while the corresponding 5\% critical value (interpolated from those reported in Pesaran, 2007, and those for a standard ADF test when N=1) are given in the columns headed 5\% critical. ** indicates the rejection of the null hypothesis that all the countries' series in the panel are I(1) at the $5 \%$ level. When the null hypothesis is rejected the first column, headed Country excluded, gives the three letter country identifier for the country to be excluded from the next test in the SPSM sequence. The first country specified is for the Intercept only case and the second country identifier is given for the Intercept and trend case.

Table A3 reports Pesaran's (2007) panel unit root test using the SPSM procedure applied to the first difference of the variables tested in Table A2. The unit root test results based upon the Pesaran (2007) method suggest that $\ln \left(H P_{t}\right)$ is at least $I(2)$ for all countries except UKD, where it is $I(1)$. In contrast, the inequality measures are $I(1)$ for most (13 to 15$)$ nations and $I(2)$ for the remaining (3 to 5) states. ${ }^{32}$ For $\ln \left(G D P p c_{t}\right) 7$ countries' series are $I(1)$ (AUS, BEL, DEN,

${ }^{32}$ GINI $_{t}$ is $I(1)$ for 13 countries (CAN, DEN, FIN, FRA, GER, ITA, JAP, KOR, NET, NEW, NOR, SWE and the USA) and at least $I(2)$ for 5 countries (AUS, BEL, IRE, SPA and UKD). Top $5 \%_{t}$ is $I(1)$ for 13 countries (CAN, DEN, FIN, FRA, GER, ITA, JAP, KOR, NET, NEW, NOR, SWE and the USA) and at least $I(2)$ for 5 countries 
ITA, KOR, UKD and the USA) and the 11 remaining countries' series are at least $I(2)$. All 18 nations series are $I(2)$ for $\ln \left(\operatorname{Pop}_{t}\right)$. Since $\Delta r_{t}$ is stationary for all countries, $r_{t}$ is $I(0)$ around a constant mean for 7 countries' series (BEL, CAN, ITA, KOR, NET, SPA and SWE), no nations' series are trend stationary and the 11 remaining countries' series are $I(1)$.

Table A3: Pesaran's (2007) panel unit root test applied to differenced data with the SPSM procedure

\begin{tabular}{|c|c|c|c|c|c|c|}
\hline \multicolumn{7}{|c|}{ Variable: $\Delta \ln \left(H P_{t}\right)$} \\
\hline & \multicolumn{3}{|c|}{ Intercept only } & \multicolumn{3}{|c|}{ Intercept and trend } \\
\hline $\mathbf{N}$ & $\begin{array}{c}\text { Country } \\
\text { excluded }\end{array}$ & Statistic & $\begin{array}{c}5 \% \\
\text { critical }\end{array}$ & Country excluded & Statistic & $\begin{array}{c}5 \% \\
\text { critical }\end{array}$ \\
\hline 18 & UKD & $-3.369^{* * *}$ & -3.337 & None & -3.728 & -3.859 \\
\hline 17 & None & -3.230 & -3.341 & & & \\
\hline \multicolumn{7}{|c|}{ Variable: $\Delta G I N I_{t}$} \\
\hline 18 & GER & $-4.891^{* *}$ & -3.337 & GER & $-5.215^{* *}$ & -3.858 \\
\hline 17 & KOR & $-4.775^{* *}$ & -3.341 & FIN & $-4.974^{* *}$ & -3.860 \\
\hline 16 & FRA & $-4.679^{* * *}$ & -3.345 & KOR & $-4.923^{* *}$ & -3.860 \\
\hline 15 & FIN & $-4.466^{* *}$ & -3.348 & FRA & $-4.821^{* *}$ & -3.862 \\
\hline 14 & JAP & $-4.293^{* * *}$ & -3.348 & NEW & $-4.697^{* * *}$ & -3.861 \\
\hline 13 & SWE & $-4.162^{* *}$ & -3.347 & JAP & $-4.551^{* * *}$ & -3.859 \\
\hline 12 & CAN & $-4.285^{* *}$ & -3.347 & SWE & $-4.424^{* *}$ & -3.857 \\
\hline 11 & NEW & $-4.165^{* * *}$ & -3.346 & CAN & $-4.231^{* * *}$ & -3.854 \\
\hline 10 & NOR & $-3.986^{* * *}$ & -3.346 & NOR & $-4.107^{* *}$ & -3.852 \\
\hline 9 & USA & $-3.822^{* *}$ & -3.303 & USA & $-3.975^{* *}$ & -3.819 \\
\hline 8 & ITA & $-3.707^{* * *}$ & -3.259 & UKD & $-3.855^{* *}$ & -3.786 \\
\hline 7 & NET & $-3.572^{* * *}$ & -3.216 & None & -3.686 & -3.753 \\
\hline 6 & DEN & $-3.512^{* * *}$ & -3.172 & & & \\
\hline 5 & None & -3.124 & -3.129 & & & \\
\hline \multicolumn{7}{|c|}{ Variable: $\Delta$ Top $5 \%_{t}$} \\
\hline 18 & GER & $-5.072^{* * *}$ & -3.336 & GER & $-5.058^{* *}$ & -3.858 \\
\hline 17 & KOR & $-4.734^{* * *}$ & -3.340 & FRA & $-4.871^{* * *}$ & -3.860 \\
\hline 16 & FRA & $-4.633^{* *}$ & -3.344 & FIN & $-4.770^{* *}$ & -3.862 \\
\hline 15 & FIN & $-4.493^{* *}$ & -3.348 & NEW & $-4.635^{* *}$ & -3.863 \\
\hline 14 & CAN & $-4.320^{* *}$ & -3.348 & CAN & $-4.553^{* *}$ & -3.862 \\
\hline 13 & JAP & $-4.206^{* *}$ & -3.347 & AUS & $-4.460^{* *}$ & -3.860 \\
\hline 12 & SWE & $-4.069^{* *}$ & -3.347 & ITA & $-4.388^{* *}$ & -3.857 \\
\hline 11 & USA & $-4.156^{* * *}$ & -3.346 & DEN & $-4.268^{* * *}$ & -3.855 \\
\hline 10 & NOR & $-4.073^{* * *}$ & -3.346 & USA & $-4.198^{* *}$ & -3.853 \\
\hline 9 & NEW & $-3.906^{* * *}$ & -3.303 & UKD & $-4.034^{* *}$ & -3.820 \\
\hline 8 & ITA & $-3.741^{* * *}$ & -3.259 & NOR & $-3.937^{* *}$ & -3.788 \\
\hline 7 & NET & $-3.576^{* *}$ & -3.216 & KOR & $-3.825^{* *}$ & -3.755 \\
\hline 6 & DEN & $-3.515^{* * *}$ & -3.172 & None & -3.687 & -3.720 \\
\hline 5 & None & -3.099 & -3.129 & & & \\
\hline
\end{tabular}

(AUS, BEL, IRE, SPA and UKD). $\ln \left(V A R_{t}\right.$ ) is $I(1)$ for 15 countries (BEL, CAN, DEN, FIN, FRA, GER, IRE, ITA, JAP, KOR, NET, NEW, NOR, SWE and USA) and at least $I(2)$ for 3 countries (AUS, SPA and UKD). $\ln \left(T o p 5 \$_{t}\right)$ is $I(1)$ for 15 countries (BEL, CAN, DEN, FIN, FRA, GER, IRE, ITA, JAP, KOR, NET, NEW, NOR, SWE and the USA) and at least $I(2)$ for 3 countries (AUS, SPA and UKD). 
Table A3 (continued)

\begin{tabular}{|c|c|c|c|c|c|c|}
\hline \multicolumn{7}{|c|}{ Variable: $\Delta \ln \left(V A R_{t}\right)$} \\
\hline & \multicolumn{3}{|c|}{ Intercept only } & \multicolumn{3}{|c|}{ Intercept and trend } \\
\hline $\mathbf{N}$ & $\begin{array}{c}\text { Country } \\
\text { excluded }\end{array}$ & Statistic & $\begin{array}{c}5 \% \\
\text { critical }\end{array}$ & $\begin{array}{r}\text { Country } \\
\text { excluded }\end{array}$ & Statistic & $\begin{array}{c}5 \% \\
\text { critical }\end{array}$ \\
\hline 18 & FIN & $-5.180^{* *}$ & -3.336 & FIN & $-5.258^{* *}$ & -3.857 \\
\hline 17 & GER & $-5.075^{* *}$ & -3.340 & GER & $-5.191^{* *}$ & -3.859 \\
\hline 16 & FRA & $-4.972^{* *}$ & -3.344 & FRA & $-4.963^{* *}$ & -3.861 \\
\hline 15 & NEW & $-4.786^{* *}$ & -3.349 & NEW & $-4.876^{* *}$ & -3.863 \\
\hline 14 & JAP & $-4.748^{* *}$ & -3.349 & DEN & $-4.842^{* *}$ & -3.862 \\
\hline 13 & SWE & $-4.648^{* *}$ & -3.348 & USA & $-4.683^{* *}$ & -3.860 \\
\hline 12 & NOR & $-4.584^{* *}$ & -3.347 & KOR & $-4.631^{* * *}$ & -3.858 \\
\hline 11 & KOR & $-4.575^{* *}$ & -3.347 & IRE & $-4.534^{* *}$ & -3.856 \\
\hline 10 & ITA & $-4.413^{* *}$ & -3.347 & JAP & $-4.445^{* *}$ & -3.854 \\
\hline 9 & IRE & $-4.230^{* *}$ & -3.304 & SWE & $-4.238^{* *}$ & -3.820 \\
\hline 8 & NET & $-4.104^{* *}$ & -3.260 & NET & $-4.158^{* *}$ & -3.786 \\
\hline 7 & CAN & $-4.044^{* *}$ & -3.217 & NOR & $-4.043^{* *}$ & -3.753 \\
\hline 6 & USA & $-4.006^{* *}$ & -3.174 & None & -3.699 & -3.721 \\
\hline 5 & BEL & $-4.015^{* *}$ & -3.131 & & & \\
\hline 4 & DEN & $-3.880^{* * *}$ & -3.087 & & & \\
\hline 3 & None & -2.949 & -3.042 & & & \\
\hline \multicolumn{7}{|c|}{ Variable: $\Delta \ln \left(\operatorname{Top} 5 \$_{t}\right)$} \\
\hline 18 & FIN & $-5.154^{* *}$ & -3.336 & FIN & $-5.230^{* * *}$ & -3.857 \\
\hline 17 & GER & $-5.046^{* *}$ & -3.340 & GER & $-5.159^{* *}$ & -3.859 \\
\hline 16 & FRA & $-4.944^{* *}$ & -3.344 & FRA & $-5.050^{* *}$ & -3.860 \\
\hline 15 & NEW & $-4.764^{* *}$ & -3.348 & DEN & $-4.867^{* *}$ & -3.863 \\
\hline 14 & DEN & $-4.631^{* * *}$ & -3.348 & NEW & $-4.657^{* *}$ & -3.861 \\
\hline 13 & KOR & $-4.557^{* * *}$ & -3.348 & KOR & $-4.597^{* *}$ & -3.859 \\
\hline 12 & ITA & $-4.508^{* *}$ & -3.348 & USA & $-4.548^{* *}$ & -3.857 \\
\hline 11 & NET & $-4.479^{* *}$ & -3.346 & ITA & $-4.478^{* *}$ & -3.855 \\
\hline 10 & IRE & $-4.429^{* *}$ & -3.346 & NET & $-4.467^{* *}$ & -3.852 \\
\hline 9 & JAP & $-4.349^{* * *}$ & -3.303 & IRE & $-4.394^{* *}$ & -3.819 \\
\hline 8 & SWE & $-4.160^{* * *}$ & -3.259 & BEL & $-4.324^{* *}$ & -3.786 \\
\hline 7 & CAN & $-3.845^{* *}$ & -3.216 & SWE & $-4.282^{* * *}$ & -3.753 \\
\hline 6 & NOR & $-3.691^{* *}$ & -3.172 & JAP & $-4.107^{* *}$ & -3.720 \\
\hline 5 & BEL & $-3.442^{* *}$ & -3.129 & None & -3.669 & -3.687 \\
\hline 4 & USA & $-3.122^{* *}$ & -3.086 & & & \\
\hline 3 & None & -2.753 & -3.042 & & & \\
\hline \multicolumn{7}{|c|}{ Variable: $\Delta \ln \left(G D P p c_{t}\right)$} \\
\hline 18 & BEL & $-4.108^{* *}$ & -3.336 & BEL & $-4.278^{* *}$ & -3.858 \\
\hline 17 & AUS & $-4.005^{* *}$ & -3.340 & AUS & $-4.145^{* *}$ & -3.860 \\
\hline 16 & UKD & $-3.861^{* *}$ & -3.344 & ITA & $-3.971^{* *}$ & -3.861 \\
\hline 15 & DEN & $-3.773^{* *}$ & -3.348 & UKD & $-3.919^{* *}$ & -3.863 \\
\hline 14 & ITA & $-3.751^{* *}$ & -3.348 & DEN & $-3.863^{* *}$ & -3.860 \\
\hline 13 & USA & $-3.682^{* *}$ & -3.347 & None & -3.826 & -3.858 \\
\hline 12 & KOR & $-3.575^{* *}$ & -3.347 & & & \\
\hline 11 & None & -3.315 & -3.346 & & & \\
\hline \multicolumn{7}{|c|}{ Variable: $\Delta \ln \left(\mathrm{Pop}_{t}\right)$} \\
\hline 18 & None & -1.715 & -3.339 & None & -2.235 & -3.862 \\
\hline
\end{tabular}


Table A3 (continued)

\begin{tabular}{|c|c|c|c|c|c|c|}
\hline \multicolumn{7}{|c|}{ Variable: $\Delta \boldsymbol{r}_{\boldsymbol{t}}$} \\
\hline $\mathrm{N}$ & \multicolumn{7}{|c|}{ Intercept only } & \multicolumn{2}{c|}{ Intercept and trend } \\
\hline & $\begin{array}{c}\text { Country } \\
\text { excluded }\end{array}$ & Statistic & $\begin{array}{c}5 \% \\
\text { critical }\end{array}$ & Country excluded & Statistic & $\begin{array}{c}5 \% \\
\text { critical }\end{array}$ \\
\hline 18 & SWE & $-5.813^{* *}$ & -3.338 & SWE & $-5.815^{* *}$ & -3.860 \\
\hline 17 & NEW & $-5.762^{* *}$ & -3.342 & NEW & $-5.802^{* *}$ & -3.862 \\
\hline 16 & SPA & $-5.749^{* *}$ & -3.346 & SPA & $-5.792^{* *}$ & -3.863 \\
\hline 15 & DEN & $-5.672^{* *}$ & -3.350 & UKD & $-5.699^{* *}$ & -3.865 \\
\hline 14 & UKD & $-5.725^{* *}$ & -3.349 & DEN & $-5.752^{* *}$ & -3.863 \\
\hline 13 & NOR & $-5.694^{* *}$ & -3.349 & NOR & $-5.716^{* *}$ & -3.861 \\
\hline 12 & CAN & $-5.597^{* *}$ & -3.349 & CAN & $-5.573^{* *}$ & -3.859 \\
\hline 11 & AUS & $-5.540^{* *}$ & -3.348 & AUS & $-5.509^{* *}$ & -3.856 \\
\hline 10 & IRE & $-5.510^{* *}$ & -3.347 & IRE & $-5.461^{* *}$ & -3.854 \\
\hline 9 & JAP & $-5.416^{* *}$ & -3.305 & JAP & $-5.293^{* *}$ & -3.822 \\
\hline 8 & KOR & $-5.317^{* *}$ & -3.262 & KOR & $-5.189^{* *}$ & -3.789 \\
\hline 7 & NET & $-5.140^{* *}$ & -3.217 & NET & $-5.023^{* *}$ & -3.754 \\
\hline 6 & FRA & $-4.894^{* *}$ & -3.174 & FRA & $-4.820^{* *}$ & -3.723 \\
\hline 5 & USA & $-4.678^{* *}$ & -3.130 & FIN & $-4.541^{* *}$ & -3.689 \\
\hline 4 & GER & $-4.901^{* *}$ & -3.086 & GER & $-4.537^{* *}$ & -3.655 \\
\hline 3 & FIN & $-4.873^{* *}$ & -3.043 & USA & $-4.584^{* *}$ & -3.621 \\
\hline 2 & ITA & $-4.309^{* *}$ & -2.999 & ITA & $-4.234^{* *}$ & -3.588 \\
\hline 1 & BEL & $-7.014^{* *}$ & -2.951 & BEL & $-7.290^{* *}$ & -3.548 \\
\hline
\end{tabular}

Table notes. See Table A2 notes except the column headed Country excluded indicates a country's series identified as not rejecting the unit root null. An entry of "None" in this column means that the unit root null cannot be rejected for all $N$ remaining countries included in the panel unit root test.

The results based on the Pesaran (2007) test suggest that the necessary condition for cointegration between $\ln \left(H P_{t}\right)$ and all of the inequality measures as well as $r_{t}$ is violated for most countries. However, given that we expect $\ln \left(H P_{t}\right)$ to be $I(1)$ we consider the possibility that this result is due to low power (possibly due to structural breaks) and, in our cointegration analysis, we treat $\ln \left(H P_{t}\right)$, and all measures of inequality, as if they are $I(1)$ for all countries. ${ }^{33}$ If $\ln \left(H P_{t}\right)$ is $I(2)$ for most countries it will not cointegrate with the generally $I(1)$ inequality variables for those countries and our cointegration test results will reveal this.

Similarly, the finding that many [all] countries' $\ln \left(G D P p c_{t}\right)\left[\ln \left(P o p_{t}\right)\right]$ series are at least I(2) may also be due to structural breaks and we consider the possibility that this [these] series is [are] $I(1)$ in our cointegration analysis. Further, $r_{t}$ being $I(0)$ for many countries and no more

\footnotetext{
${ }^{33}$ It may be that for some countries both $\ln (H P)$ and the inequality variable are found to be $I(2)$ according to our test results and in fact are both $I(1)$ around structural breaks and they are found to cointegrate because they cointegrate and co-break.
} 
than $I(1)$ for any country suggests that it is unlikely to cointegrate with $\ln \left(H P_{t}\right)$, on its own, for many nations. However, when we apply unit root tests that allow for nonlinear adjustment we find far more widespread evidence that most countries' series are $I(1)$ according to at least one test, and this therefore helps support our treatment of the series (except interest rates) as satisfying the necessary condition for cointegration. The results from these nonlinear unit root tests are presented and discussed below.

Table A4 reports Cerrato et al.'s (2011) heterogeneous nonlinear panel unit root tests (using the SPSM procedure) for the levels of the variables tested above. This test accommodates crosssectional dependence and extends the Pesaran et al. (2007) method that assumes a linear adjustment process by allowing nonlinear adjustment. Such nonlinear adjustment could look like structural breaks without being confined to a single once-and-for-all jump at one particular point in time. Hence, when there is such nonlinear adjustment Cerrato et al.'s (2011) test should be more powerful than that of Pesaran (2007).

The results reported in Table A4 indicate that all series are at least $I(1)$ for all countries except for $\ln \left(H P_{t}\right)$, where there is evidence of stationarity for 3 countries (FIN, JAP and NEW), $\operatorname{GINI}_{t}$ where there is evidence of stationarity for 1 country (NET) and $r_{t}$ where there is evidence of stationarity for 8 countries (BEL, FIN, GER, ITA, NEW, NOR, SPA and SWE) and trend stationarity for 1 country (CAN). Excepting these minor anomalies (that may be due to, for example, Type I errors) these results broadly confirm those from Pesaran's (2007) test that all 7 (non interest rate) series are at least $I(1)$ for all countries. 
Table A4: Cerrato et al.'s (2011) nonlinear panel unit root test applied to levels data with SPSM

\begin{tabular}{|c|c|c|c|c|c|c|}
\hline \multicolumn{7}{|c|}{ Variable: $\ln \left(H P_{t}\right)$} \\
\hline & \multicolumn{3}{|c|}{ Intercept only } & \multicolumn{3}{|c|}{ Intercept and trend } \\
\hline $\mathbf{N}$ & $\begin{array}{c}\text { Country } \\
\text { excluded }\end{array}$ & Statistic & $\begin{array}{c}5 \% \\
\text { critical }\end{array}$ & $\begin{array}{r}\text { Country } \\
\text { excluded }\end{array}$ & Statistic & $\begin{array}{c}5 \% \\
\text { critical }\end{array}$ \\
\hline 18 & NEW & $-2.385^{* *}$ & -2.021 & None & -2.263 & -2.379 \\
\hline 17 & JAP & $-2.151^{* *}$ & -2.027 & & & \\
\hline 16 & FIN & $-2.040^{* *}$ & -2.033 & & & \\
\hline 15 & None & -1.864 & -2.039 & & & \\
\hline \multicolumn{7}{|c|}{ Variable: $G I N I_{t}$} \\
\hline 18 & NET & $-2.113^{* *}$ & -2.023 & None & -2.102 & -2.380 \\
\hline 17 & None & -1.810 & -2.029 & & & \\
\hline \multicolumn{7}{|c|}{ Variable: $\operatorname{Top} 5 \%_{t}$} \\
\hline 18 & None & -2.014 & -2.023 & None & -2.119 & -2.381 \\
\hline \multicolumn{7}{|c|}{ Variable: $\ln \left(V A R_{t}\right)$} \\
\hline 18 & None & -1.922 & -2.024 & None & -1.888 & -2.381 \\
\hline \multicolumn{7}{|c|}{ Variable: $\ln \left(\right.$ Top $\left.5 \$_{t}\right)$} \\
\hline 18 & None & -1.940 & -2.024 & None & -2.036 & -2.381 \\
\hline \multicolumn{7}{|c|}{ Variable: $\ln \left(G D P p c_{t}\right)$} \\
\hline 18 & None & -1.453 & -2.023 & None & -1.880 & -2.381 \\
\hline \multicolumn{7}{|c|}{ Variable: $\ln \left(\mathrm{Pop}_{t}\right)$} \\
\hline 18 & None & -1.799 & -2.020 & None & -1.235 & -2.377 \\
\hline \multicolumn{7}{|c|}{ Variable: $r_{t}$} \\
\hline 18 & NEW & $-2.822^{* *}$ & -2.023 & NEW & $-2.981^{* *}$ & -2.381 \\
\hline 17 & FIN & $-2.772^{* *}$ & -2.030 & FIN & $-2.841^{* *}$ & -2.377 \\
\hline 16 & SPA & $-2.426^{* *}$ & -2.036 & CAN & $-2.650^{* *}$ & -2.373 \\
\hline 15 & GER & $-2.709^{* *}$ & -2.042 & ITA & $-2.463^{* *}$ & -2.370 \\
\hline 14 & BEL & $-2.587^{* *}$ & -2.048 & None & -2.337 & -2.366 \\
\hline 13 & SWE & $-2.456^{* *}$ & -2.055 & & & \\
\hline 12 & NOR & $-2.450^{* *}$ & -2.060 & & & \\
\hline 11 & ITA & $-2.144^{* *}$ & -2.066 & & & \\
\hline 10 & None & -2.002 & -2.072 & & & \\
\hline
\end{tabular}

Table notes. See Table A3 notes except critical values are interpolated from those reported in Cerrato et al. (2011), Table 13 and Table 14, as well as Cerrato et al. (2013).

Table A5 reports Cerrato et al.'s (2011) heterogeneous nonlinear panel unit root test using the SPSM procedure applied to the first difference of the variables tested in Table A4. The unit root test results based upon the Cerrato et al.'s (2011) method suggest that $\ln \left(H P_{t}\right)$ is $I(0)$ around a constant mean for 3 countries (FIN, JAP, NEW), trend stationary for 0 countries, $I(1)$ for 12 countries (AUS, CAN, DEN, GER, ITA, KOR, NET, NOR, SPA, SWE, UKD and the USA) and at least $I$ (2) for 3 countries (BEL, FRA and IRE). Similarly, the inequality measures 
are $I(1)$ for most (9 to 15$)$ nations and $I(1)$ for the remaining states. ${ }^{34} \ln \left(G D P p c_{t}\right)$ is $I(0)$ around a constant mean for 0 countries, trend stationary for 0 countries, $I(1)$ for 16 countries (AUS, BEL, CAN, DEN, FIN, FRA, GER, IRE, ITA, JAP, KOR, NET, SPA, SWE, UKD and the USA) and at least $I(2)$ for 2 countries (NEW and NOR). All 18 nations series are $I(2)$ for $\ln \left(P o p_{t}\right) \cdot r_{t}$ is $I(0)$ around a constant mean for 8 countries' series (BEL, FIN, GER, ITA, NEW, NOR, SPA and SWE), trend stationary for 1 country (CAN), I(1) for 4 countries (AUS, FRA, IRE and JAP) and at least $I(2)$ for 5 countries (DEN, KOR, NET, UKD and the USA).

Considering both panel unit root tests (allowing for both linear and nonlinear adjustment) we favour a lower order of integration if either test indicates a lower order because this is likely to reflect a test's greater power when the correct form of alternative hypothesis is specified. Further, we reject a finding that either $\ln \left(H P_{t}\right)$ or $\ln \left(G D P p c_{t}\right)$ is $I(0)$ because in the growing and inflationary economies that we consider we believe it is unrealistic to regard either of these series as anything other than nonstationary. Combining these prior beliefs with our unit root tests we argue that all series are $I(1)$ for the vast majority of countries (with the exception of interest rates where 11 countries' series are $I(0)$ and 7 are $I(1)) .{ }^{35}$ Further, any anomalies may

\footnotetext{
${ }^{34} \mathrm{GINI}_{t}$ is $I(0)$ around a constant mean for 1 country (NET), trend stationary for 0 countries, $I(1)$ for 12 countries (AUS, CAN, DEN, FIN, FRA, IRE, JAP, NEW, NOR, SWE, UKD and the USA) and at least $I(2)$ for 5 countries (BEL, GER, ITA, KOR and SPA). Top $5 \%_{t}$ is $I(1)$ for 13 countries (CAN, DEN, FIN, FRA, GER, IRE, ITA, JAP, NET, NEW, NOR, SWE and the USA) and at least $I(2)$ for 5 countries (AUS, BEL, KOR, SPA and UKD). $\ln \left(V A R_{t}\right)$ is $I(1)$ for 9 countries (CAN, DEN, FIN, FRA, IRE, NEW, NOR, SPA and UKD) and at least $I(2)$ for 9 countries (AUS, BEL, GER, ITA, JAP, KOR, NET, SWE and the USA). $\ln \left(T o p 5 \$_{t}\right)$ is $I(1)$ for 15 countries (BEL, CAN, DEN, FIN, FRA, GER, IRE, ITA, JAP, KOR, NEW, NOR, SWE, UKD and the USA) and at least $I(2)$ for 3 countries (AUS, NET and SPA).

${ }^{35}$ Hence, our findings are that $\ln \left(H P_{t}\right)$ is $I(1)$ for 13 countries (AUS, CAN, DEN, GER, ITA, JAP, KOR, NET, NOR, SPA, SWE, UKD and the USA) and for the 5 countries (BEL, FIN, FRA, NEW and IRE) where it is found to be at least $I(2)$ we consider the possibility that it is $I(1)$ around structural breaks. Similarly, $\ln \left(G D P p c_{t}\right)$ is I(1) for 16 countries (AUS, BEL, CAN, DEN, FIN, FRA, GER, IRE, ITA, JAP, KOR, NET, SPA, SWE, UKD and the USA) and for the 2 countries (NEW and NOR) where it is found to be at least $I(2)$ we consider the possibility it is $I(1)$ around structural breaks. Although $G I N I_{t}$ is evidently $I(0)$ for 1 country (NET) we consider the possibility that this is due to anomalies such as such as Type I errors and treat it as $I(1)$ for this country. GINI $I_{t}$ is $I(1)$ according to at least one of the tests for another 15 countries (AUS, CAN, DEN, FIN, FRA, GER, IRE, ITA, JAP, KOR, NEW, NOR, SWE, UKD and the USA), and for the 2 countries (BEL, and SPA) where it is found to be at least $I(2)$ we consider the possibility it is $I(1)$ around structural breaks. Top $5 \%_{t}$ is $I(1)$ for 14 countries (CAN, DEN, FIN, FRA, GER, IRE, ITA, JAP, KOR, NET, NEW, NOR, SWE and the USA), and for the 4 countries (AUS, BEL, SPA and UKD) where it is found to be at least $I(2)$ we consider the possibility it is $I(1)$ around structural breaks. $\ln \left(V A R_{t}\right)$ is $I(1)$ for 17 countries (BEL, CAN, DEN, FIN, FRA, GER, IRE, ITA, JAP, KOR, NET, NEW, NOR, SPA, SWE, UKD and the USA), and for the 1 country (AUS) where it is found to be at least $I(2)$ we consider the possibility it is $I(1)$ around structural breaks. $\ln \left(T o p 5 \$_{t}\right)$ is $I(1)$ for 16 countries (BEL,
} 
be due to factors such as Type I errors. Hence, we treat all series as if they are $I(1)$, satisfying the necessary condition for cointegration, and proceed to conduct tests of cointegration. ${ }^{36}$ If the assumption that the necessary condition for cointegration being satisfied is incorrect this will likely be manifest in our tests rejecting cointegration (the most likely series where this could be the case is the real interest rate) and/or making the estimated cointegrating equations theoretically implausible.

CAN, DEN, FIN, FRA, GER, IRE, ITA, JAP, KOR, NET, NEW, NOR, SWE, UKD and the USA), and for the 2 countries (AUS and SPA) where it is found to be at least $I(2)$ we consider the possibility it is $I(1)$ around structural breaks. All 18 nations series are $I(2)$ for $\ln \left(P o p_{t}\right)$, however, we consider the possibility that it is $I(1)$ around structural breaks for all countries. $r_{t}$ is $I(0)$ for 11 countries' series (BEL, CAN, FIN, GER, ITA, KOR, NET, NEW, NOR, SPA and SWE) and $I$ (1) for 7 countries (AUS, DEN, FRA, IRE, JAP, UKD and the USA). While we consider the possibility that $r_{t}$ is $I(1)$ for all countries we recognize that it may well be $I(0)$ for most countries and, as for any other cases where the treatment of a series as $I(1)$ turns out to be incorrect, we believe that this will likely become apparent from the cointegration test results and the theoretical plausibility of the estimated cointegrating equations (which will likely to cause us to reject such specifications).

${ }^{36}$ If some of the series are $I(0)$ this should not be an issue because the ADL method can identify error-correction relationships when some series are $I(1)$ and others are $I(0)$ - although the critical values employed with the Westerlund (2007) method assume I(1) variables. Further, if some series are trend stationary this can be accounted for in our application of the Westerlund (2007) procedure because we apply the method incorporating just an intercept and both an intercept and linear trend. 
Table A5: Cerrato et al.'s (2011) nonlinear panel unit root test applied to difference data with SPSM

\begin{tabular}{|c|c|c|c|c|c|c|}
\hline \multicolumn{7}{|c|}{ Variable: $\Delta \ln \left(H P_{t}\right)$} \\
\hline & \multicolumn{3}{|c|}{ Intercept only } & \multicolumn{3}{|c|}{ Intercept and trend } \\
\hline $\mathbf{N}$ & $\begin{array}{l}\text { Country } \\
\text { excluded }\end{array}$ & Statistic & $\begin{array}{c}5 \% \\
\text { critical }\end{array}$ & $\begin{array}{c}\text { Country } \\
\text { excluded }\end{array}$ & Statistic & $\begin{array}{c}5 \% \\
\text { critical }\end{array}$ \\
\hline 18 & NET & $-3.212^{* *}$ & -2.021 & JAP & $-3.524^{* *}$ & -2.377 \\
\hline 17 & JAP & $-3.001^{* *}$ & -2.027 & NET & $-3.345^{* *}$ & -2.373 \\
\hline 16 & SWE & $-2.882^{* *}$ & -2.033 & DEN & $-3.176^{* *}$ & -2.369 \\
\hline 15 & KOR & $-2.712^{* * *}$ & -2.039 & SWE & $-2.963^{* * *}$ & -2.366 \\
\hline 14 & NOR & $-2.692^{* *}$ & -2.045 & NOR & $-2.757^{* *}$ & -2.362 \\
\hline 13 & DEN & $-2.700^{* *}$ & -2.050 & AUS & $-2.843^{* *}$ & -2.358 \\
\hline 12 & AUS & $-2.462^{* * *}$ & -2.057 & KOR & $-2.707^{* * *}$ & -2.354 \\
\hline 11 & ITA & $-2.449^{* *}$ & -2.063 & ITA & $-2.614^{* *}$ & -2.351 \\
\hline 10 & UKD & $-2.332^{* *}$ & -2.070 & USA & $-2.614^{* *}$ & -2.351 \\
\hline 9 & GER & $-2.343^{* *}$ & -2.076 & UKD & $-2.408^{* * *}$ & -2.343 \\
\hline 8 & USA & $-2.278^{* *}$ & -2.082 & GER & $-2.504^{* *}$ & -2.340 \\
\hline 7 & CAN & $-2.226^{* *}$ & -2.088 & CAN & $-2.393^{* *}$ & -2.336 \\
\hline 6 & SPA & $-2.151^{* *}$ & -2.094 & None & -2.326 & -2.332 \\
\hline 5 & None & -1.890 & -2.100 & & & \\
\hline \multicolumn{7}{|c|}{ Variable: $\Delta G I N I_{t}$} \\
\hline 18 & NOR & $-3.727^{* * *}$ & -2.021 & NOR & $-3.904^{* * *}$ & -2.378 \\
\hline 17 & NEW & $-3.659^{* * *}$ & -2.027 & NEW & $-3.709^{* * *}$ & -2.374 \\
\hline 16 & UKD & $-3.614^{* *}$ & -2.034 & UKD & $-3.632^{* *}$ & -2.371 \\
\hline 15 & FRA & $-3.424^{* * *}$ & -2.040 & FRA & $-3.409^{* *}$ & -2.367 \\
\hline 14 & FIN & $-3.285^{* *}$ & -2.045 & FIN & $-3.276^{* *}$ & -2.363 \\
\hline 13 & CAN & $-3.073^{* *}$ & -2.051 & CAN & $-3.071^{* *}$ & -2.359 \\
\hline 12 & JAP & $-2.904^{* *}$ & -2.057 & IRE & $-2.912^{* * *}$ & -2.355 \\
\hline 11 & NET & $-2.848^{* * *}$ & -2.063 & JAP & $-2.804^{* * *}$ & -2.351 \\
\hline 10 & SWE & $-2.715^{* *}$ & -2.069 & NET & $-2.881^{* * *}$ & -2.347 \\
\hline 9 & IRE & $-2.732^{* *}$ & -2.075 & SWE & $-2.728^{* * *}$ & -2.343 \\
\hline 8 & DEN & $-2.618^{* * *}$ & -2.081 & DEN & $-2.575^{* *}$ & -2.339 \\
\hline 7 & USA & $-2.319^{* * *}$ & -2.087 & None & -2.281 & -2.335 \\
\hline 6 & AUS & $-2.241^{* *}$ & -2.093 & & & \\
\hline 5 & None & -2.058 & -2.099 & & & \\
\hline
\end{tabular}


Table A5 (continued)

\begin{tabular}{|c|c|c|c|c|c|c|}
\hline \multicolumn{7}{|c|}{ Variable: $\Delta T o p 5 \%_{t}$} \\
\hline & \multicolumn{3}{|c|}{ Intercept only } & \multicolumn{3}{|c|}{ Intercept and trend } \\
\hline $\mathbf{N}$ & $\begin{array}{l}\text { Country } \\
\text { excluded }\end{array}$ & Statistic & $\begin{array}{c}5 \% \\
\text { critical }\end{array}$ & $\begin{array}{c}\text { Country } \\
\text { excluded }\end{array}$ & Statistic & $\begin{array}{c}5 \% \\
\text { critical }\end{array}$ \\
\hline 17 & NOR & $-3.550^{* *}$ & -2.027 & NOR & $-3.595^{* *}$ & -2.374 \\
\hline 16 & CAN & $-3.417^{* *}$ & -2.033 & NEW & $-3.468^{* * *}$ & -2.370 \\
\hline 15 & FRA & $-3.299^{* *}$ & -2.039 & CAN & $-3.351^{* *}$ & -2.367 \\
\hline 14 & FIN & $-3.181^{* *}$ & -2.045 & FIN & $-3.214^{* *}$ & -2.363 \\
\hline 13 & NEW & $-2.935^{* *}$ & -2.051 & FRA & $-2.973^{* * *}$ & -2.359 \\
\hline 12 & NET & $-2.769^{* * *}$ & -2.057 & NET & $-2.785^{* * *}$ & -2.355 \\
\hline 11 & JAP & $-2.655^{* *}$ & -2.063 & JAP & $-2.663^{* *}$ & -2.351 \\
\hline 10 & SWE & $-2.748^{* *}$ & -2.070 & SWE & $-2.627^{* * *}$ & -2.347 \\
\hline 9 & DEN & $-2.645^{* * *}$ & -2.075 & DEN & $-2.666^{* * *}$ & -2.343 \\
\hline 8 & USA & $-2.404^{* *}$ & -2.081 & IRE & $-2.440^{* *}$ & -2.339 \\
\hline 7 & IRE & $-2.297^{* *}$ & -2.087 & None & -2.316 & -2.335 \\
\hline 6 & ITA & $-2.251^{* * *}$ & -2.093 & & & \\
\hline 5 & GER & $-2.759^{* *}$ & -2.100 & & & \\
\hline 4 & None & -2.044 & -2.105 & & & \\
\hline \multicolumn{7}{|c|}{ Variable: $\Delta \ln \left(V A R_{t}\right)$} \\
\hline 18 & NOR & $-3.763^{* *}$ & -2.022 & NOR & $-3.780^{* *}$ & -2.378 \\
\hline 17 & FRA & $-3.569^{* *}$ & -2.028 & FRA & $-3.370^{* *}$ & -2.374 \\
\hline 16 & FIN & $-3.472^{* *}$ & -2.033 & FIN & $-3.492^{* *}$ & -2.370 \\
\hline 15 & SPA & $-3.259^{* *}$ & -2.039 & GER & $-3.290^{* * *}$ & -2.366 \\
\hline 14 & DEN & $-3.287^{* *}$ & -2.046 & DEN & $-3.374^{* * *}$ & -2.363 \\
\hline 13 & IRE & $-2.607^{* *}$ & -2.051 & UKD & $-2.908^{* *}$ & -2.359 \\
\hline 12 & UKD & $-2.499^{* *}$ & -2.057 & NEW & $-2.726^{* *}$ & -2.355 \\
\hline 11 & NEW & $-2.381^{* *}$ & -2.063 & IRE & $-2.726^{* *}$ & -2.351 \\
\hline 10 & CAN & $-2.182^{* *}$ & -2.069 & KOR & $-2.857^{* *}$ & -2.348 \\
\hline 9 & None & -1.964 & -2.074 & JAP & $-2.631^{* *}$ & -2.343 \\
\hline 8 & & & & SWE & $-2.494^{* *}$ & -2.339 \\
\hline 7 & & & & CAN & $-2.437^{* *}$ & -2.336 \\
\hline 6 & & & & None & -2.094 & -2.331 \\
\hline \multicolumn{7}{|c|}{ Variable: $\Delta \ln \left(T o p 5 \$_{t}\right)$} \\
\hline 18 & NOR & $-3.912^{* *}$ & -2.022 & NOR & $-3.938^{* *}$ & -2.379 \\
\hline 17 & FRA & $-3.727^{* *}$ & -2.028 & FRA & $-3.758^{* *}$ & -2.375 \\
\hline 16 & FIN & $-3.620^{* *}$ & -2.033 & GER & $-3.654^{* *}$ & -2.370 \\
\hline 15 & GER & $-3.416^{* *}$ & -2.039 & FIN & $-3.404^{* *}$ & -2.367 \\
\hline 14 & DEN & $-3.444^{* *}$ & -2.046 & DEN & $-3.470^{* *}$ & -2.363 \\
\hline 13 & IRE & $-3.067^{* *}$ & -2.052 & UKD & $-3.097^{* *}$ & -2.359 \\
\hline 12 & CAN & $-2.975^{* *}$ & -2.058 & IRE & $-2.942^{* *}$ & -2.355 \\
\hline 11 & UKD & $-2.892^{* *}$ & -2.064 & SWE & $-2.830^{* *}$ & -2.351 \\
\hline 10 & SWE & $-2.758^{* *}$ & -2.070 & JAP & $-3.031^{* *}$ & -2.348 \\
\hline 9 & JAP & $-2.940^{* *}$ & -2.076 & CAN & $-2.590^{* * *}$ & -2.344 \\
\hline 8 & NEW & $-2.369^{* *}$ & -2.082 & NEW & $-2.364^{* *}$ & -2.340 \\
\hline 7 & KOR & $-2.140^{* *}$ & -2.088 & None & $-2.134^{* *}$ & -2.336 \\
\hline 6 & USA & $-2.213^{* *}$ & -2.094 & & & \\
\hline 5 & ITA & $-2.131^{* *}$ & -2.100 & & & \\
\hline 4 & BEL & $-2.109^{* *}$ & -2.106 & & & \\
\hline 3 & None & -1.866 & -2.112 & & & \\
\hline
\end{tabular}


Table A5 (continued)

\begin{tabular}{|c|c|c|c|c|c|c|}
\hline \multicolumn{7}{|c|}{ Variable: $\Delta \ln \left(G D P p c_{t}\right)$} \\
\hline & \multicolumn{3}{|c|}{ Intercept only } & \multicolumn{3}{|c|}{ Intercept and trend } \\
\hline $\mathbf{N}$ & $\begin{array}{l}\text { Country } \\
\text { excluded }\end{array}$ & Statistic & $\begin{array}{c}5 \% \\
\text { critical }\end{array}$ & $\begin{array}{r}\text { Country } \\
\text { excluded }\end{array}$ & Statistic & $\begin{array}{c}5 \% \\
\text { critical }\end{array}$ \\
\hline 18 & KOR & $-3.479^{* *}$ & -2.022 & KOR & $-3.434^{* *}$ & -2.378 \\
\hline 17 & GER & $-3.359^{* *}$ & -2.028 & GER & $-3.345^{* *}$ & -2.374 \\
\hline 16 & USA & $-3.348^{* *}$ & -2.034 & USA & $-3.349^{* *}$ & -2.371 \\
\hline 15 & SPA & $-3.143^{* *}$ & -2.040 & SPA & $-3.152^{* *}$ & -2.366 \\
\hline 14 & JAP & $-3.149^{* *}$ & -2.045 & JAP & $-3.155^{* *}$ & -2.362 \\
\hline 13 & NET & $-3.126^{* *}$ & -2.051 & NET & $-3.137^{* *}$ & -2.358 \\
\hline 12 & SWE & $-3.122^{* *}$ & -2.057 & ITA & $-3.097^{* *}$ & -2.354 \\
\hline 11 & ITA & $-3.109^{* *}$ & -2.063 & SWE & $-3.088^{* *}$ & -2.350 \\
\hline 10 & AUS & $-3.087^{* *}$ & -2.069 & AUS & $-3.081^{* *}$ & -2.347 \\
\hline 9 & CAN & $-2.827^{* *}$ & -2.076 & $\mathrm{CAN}$ & $-2.780^{* *}$ & -2.342 \\
\hline 8 & BEL & $-3.001^{* *}$ & -2.081 & BEL & $-2.887^{* *}$ & -2.339 \\
\hline 7 & IRE & $-2.887^{* *}$ & -2.087 & IRE & $-2.793^{* *}$ & -2.335 \\
\hline 6 & FRA & $-2.489^{* *}$ & -2.094 & None & -2.301 & -2.331 \\
\hline 5 & FIN & $-2.526^{* *}$ & -2.100 & & & \\
\hline 4 & DEN & $-2.567^{* *}$ & -2.106 & & & \\
\hline 3 & UKD & -2.452 & -2.112 & & & \\
\hline 2 & None & -1.809 & -2.120 & & & \\
\hline \multicolumn{7}{|c|}{ Variable: $\Delta \ln \left(\mathrm{Pop}_{t}\right)$} \\
\hline 18 & None & -1.780 & -2.020 & None & -2.279 & -2.376 \\
\hline \multicolumn{7}{|c|}{ Variable: $\Delta r_{t}$} \\
\hline 18 & SWE & $-2.913^{* *}$ & -2.020 & SWE & $-2.868^{* *}$ & -2.376 \\
\hline 17 & NEW & $-2.718^{* *}$ & -2.026 & NEW & $-2.642^{* *}$ & -2.372 \\
\hline 16 & JAP & $-3.040^{* *}$ & -2.032 & JAP & $-3.143^{* *}$ & -2.369 \\
\hline 15 & IRE & $-2.535^{* *}$ & -2.535 & IRE & $-2.657^{* *}$ & -2.365 \\
\hline 14 & AUS & $-2.346^{* *}$ & -2.043 & None & -2.302 & -2.360 \\
\hline 13 & SPA & $-2.149^{* *}$ & -2.049 & & & \\
\hline 12 & $\mathrm{CAN}$ & $-2.330^{* *}$ & -2.056 & & & \\
\hline 11 & BEL & $-2.353^{* *}$ & -2.062 & & & \\
\hline 10 & FRA & $-2.306^{* *}$ & -2.068 & & & \\
\hline 9 & ITA & $-2.096^{* *}$ & -2.072 & & & \\
\hline 8 & None & -1.887 & -2.080 & & & \\
\hline
\end{tabular}

Table notes. See Table A4 notes.

\section{Additional reference for the appendix}

Cerrato, M., de Peretti, C., and Stewart, C. (2013) 'Is the consumption-income ratio stationary? Evidence from linear and nonlinear panel unit root tests for OECD and non-OECD countries', The Manchester School, 81(1), pp. 102-120. 